\title{
Increased plasma brain-derived neurotrophic factor (BDNF) as a potential biomarker for and compensatory mechanism in mild cognitive impairment: a case-control study
}

\author{
Ted Kheng Siang Ng ${ }^{1,2,3,4}$, Christina Coughlan5 ${ }^{5}$ Patricia C. Heyn ${ }^{2,6}$, Alex Tagawa ${ }^{2,6}$, \\ James J. Carollo ${ }^{2,6}$, Ee Heok Kua ${ }^{1,7}$, Rathi Mahendran ${ }^{1,7}$ \\ ${ }^{1}$ Department of Psychological Medicine, Yong Loo Lin School of Medicine, National University of Singapore, \\ Singapore 119228, Singapore \\ ${ }^{2}$ University of Colorado Anschutz Medical Campus, Aurora, CO 80045, USA \\ ${ }^{3}$ Arizona State University, Edson College of Nursing and Health Innovation, Phoenix, AZ 85004, USA \\ ${ }^{4}$ National Cheng Kung University, Institute of Behavioral Medicine, College of Medicine, Tainan 701, Taiwan \\ ${ }^{5}$ University of Colorado Alzheimer's and Cognition Center (CUACC), Department of Neurology, School of Medicine, \\ University of Colorado Anschutz Medical Campus, Aurora, CO 80045, USA \\ ${ }^{6}$ Children's Hospital Colorado, Center for Gait and Movement Analysis (CGMA), Aurora, CO 80045, USA \\ ${ }^{7}$ Department of Psychological Medicine, National University Hospital, Singapore 119228, Singapore
}

Correspondence to: Ted Kheng Siang Ng; email: a0047115@u.nus.edu

Keywords: BDNF, hs-CRP, discriminative accuracy, mild cognitive impairment, cerebral palsy

Received: May 5, 2021

Accepted: September 18, 2021

Published: October 15, 2021

Copyright: (C) $2021 \mathrm{Ng}$ et al. This is an open access article distributed under the terms of the Creative Commons Attribution License (CC BY 3.0), which permits unrestricted use, distribution, and reproduction in any medium, provided the original author and source are credited.

\section{ABSTRACT}

Background: Previous meta-analyses examining the continuum of Alzheimer's disease (AD) concluded significantly decreased peripheral brain-derived neurotrophic factor (BDNF) in AD. However, across different meta-analyses, there remain inconsistent findings on peripheral BDNF levels in individuals with mild cognitive impairment $(\mathrm{MCl})$. This issue has been attributed to the highly heterogenous clinical and laboratory factors. Thus, BDNF's level, discriminative accuracy for identifying all-cause $\mathrm{MCl}$ and its subtypes, and its associations with other biomarkers and neurocognitive domains, remain largely unknown.

Methods: To address this heterogeneity, we compared a healthy control cohort ( $n=56,45$ female) to an $\mathrm{MCl}$ cohort ( $n=40,28$ female), to determine whether plasma BDNF, hs-CRP, and DHEA-S can differentiate healthy from $\mathrm{MCl}$ individuals, including two $\mathrm{MCl}$ subtypes (amnestic [aMCl] and non-amnestic [non-aMCl]). The associations between BDNF with other biomarkers and neurocognitive tests were examined. Adults with cerebral palsy were included as sensitivity analyses.

Results: Compared to healthy controls, BDNF was significantly higher in all-cause $\mathrm{MCl}$, aMCl, and non-aMCl. Furthermore, BDNF had good (AUC $=0.84,95 \% \mathrm{Cl}=0.74$ to $0.95, \mathrm{p}<0.001$ ) and excellent discriminative accuracies ( $A U C=0.92,95 \% \mathrm{Cl}=0.84$ to $1.00, p<0.001$ ) for all-cause $\mathrm{MCl}$ and non-amnestic $\mathrm{MCl}$, respectively. BDNF was significantly and positively associated with plasma hs-CRP $(\beta=0.26,95 \% \mathrm{Cl}=0.02$ to $0.50, p=0.038)$, despite attenuated association upon controlling for $\mathrm{BMI}(\beta=0.15,95 \% \mathrm{Cl}=-0.08$ to $0.38, p=0.186)$. Multiple inverse associations between BDNF and detailed neurocognitive tests were also detected.

Conclusions: These findings suggest BDNF is increased as a compensatory mechanism in preclinical dementia, supporting the neurotrophic and partially the inflammatory hypotheses of cognitive impairment. 


\section{INTRODUCTION}

Mild cognitive impairment (MCI) is an intermediate state between normal aging and early dementia [1-3]. Individuals with MCI have an increased risk of dementia and can be broadly categorised into two subtypes with distinct clinical trajectories; amnestic-MCI (a-MCI) cases, which typically progress into Alzheimer's disease (AD), while the majority of cases with non-amnesticMCI (non-aMCI) develop non-Alzheimer's dementia [2]. Regardless of subtypes, MCI is a clinical diagnosis, made primarily based on the established gold standard Peterson's criteria [2], which relies on clinical judgement informed by reviewing participants' selfreported cognitive complaints and neurocognitive test scores. Thus, clinicians often disagree on a diagnosis of MCI, with the Cronbach alpha value for an MCI diagnosis often only slightly higher than 0.5 . Hence, an objective biomarker is much needed, particularly one which also illuminates the biological underpinnings of MCI. A biomarker has several advantages in screening and triaging a clinical diagnosis; in addition to being less time-consuming than administering a comprehensive battery of neurocognitive tests, it serves as an objective measure free from the influence of interviewer and patient bias. Biomarkers have been increasingly recognized as an important component to guide precision medicine [4], which has the goal of identifying, characterizing, and personalizing effectively, screening, diagnosis and treatments that are unique to the needs of an individual patient [4]. As such, biomarkers could assist clinicians in more accurately differentiating those with MCI from healthy aging older adults in the screening process. As MCI represents an optimal stage for initiating disease-modifying interventions, with improved screening and diagnostic accuracies, clinically-useful biomarkers would allow interventions being delivered in a more timely and targeted manner.

Biomarkers are also imperative in understanding the biological underpinnings of MCI. The neuropathologies associated with cognitive impairment (CI) and dementia are complex, multi-faceted, and interrelated. Neuropathological hallmarks of Alzheimer's dementia include beta-amyloid $(A \beta)$ deposition, tau hyperphosphorylation, and neurodegeneration $[5,6]$. The amyloid/tau/neurodegeneration $(\mathrm{A} / \mathrm{T} / \mathrm{N})$ framework [7] has thus been proposed. Several AD biomarkers, including cerebrospinal fluid (CSF) [8] and positron emission tomography (PET) imaging of amyloid and tau proteins $[9,10]$, have been extensively validated and show high sensitivities and specificities, but their levels do not provide the desired information with respect to staging the disease process. This lack of staging where someone is in the neurodegenerative disease process results primarily from a lack of consistent cut-off values for $\mathrm{A} \beta$, Tau etc. that determine when someone moves from for e.g. MCI to AD, a deficiency that needs to be urgently addressed. Several research groups have shown non-A $\beta$, non-tau (NANT) markers as candidates for neurodegeneration, with Brain-derived neurotropic factor (BDNF) serving as one example [11-15]. BDNF is a neurotrophin that promotes the survival, functions, and development of neurons [16]. BDNF also modulates cognition and memory, by promoting neurogenesis and synaptic growth, enhancing neurotransmission across synapses, and modulating synaptic plasticity [17]. It is also involved in inducing hippocampal long-term potentiation, an essential mechanism for memory formation [17]. BDNF is widely expressed in the brain, including cortex, hippocampus, and the basal forebrain regions. It crosses the blood-brain-barrier in a bidirectional manner and is thus detectable in the blood [18]. Weinstein et al. found that older adults with higher peripheral BDNF levels had lower odds of developing $\mathrm{AD}$ [19]. BDNF level was also altered in many other neurodegenerative diseases and psychiatric disorders [20-23]. Decreased BDNF levels may thus constitute a lack of trophic support, contributing to neuronal degeneration [24]. Hence, BDNF could be a candidate biomarker for neurodegeneration in MCI. We have previously conducted a meta-analysis and concluded that peripheral BDNF is significantly decreased in patients with $\mathrm{AD}$, compared to healthy controls [25]. Other metaanalyses show similar and consistent findings [26, 27]. However, no consensus had been reached regarding peripheral BDNF levels in MCI. Primary studies and even meta-analyses often present inconsistent and contradictory evidence on the levels of peripheral BDNF in MCI. One of the main explanations for such discrepant findings is the presence of significant and high heterogeneity across studies [25, 28]. Furthermore, it was proposed that MCI represents an early stage in the trajectory of dementia, where peripheral BDNF levels may be increased as a compensatory and neuroprotective strategy in response to various neuronal insults $[14,15$, 19, 27, 29]. This hypothesis is further supported by studies reporting increased peripheral BDNF levels in MCI $[14,15,30]$.

Two main sources of heterogeneity present in previous peripheral BDNF studies are clinical factors and laboratory measures. Amongst the critical clinical factors is the high heterogeneity in older adults presenting with $\mathrm{MCI}$, many having psychiatric comorbidities [25], such as major depressive disorder (MDD) and generalized anxiety disorder (GAD) [31, 32], complicating the diagnosis. Since patients with MDD and GAD have decreased peripheral BDNF levels $[23,33]$, the presence of these psychiatric co-morbidities may mask the real changes in peripheral BDNF in MCI. 
The consumption of psychotropic medications is another prominent source of heterogeneity in accurately assessing peripheral BDNF levels. Most peripheral BDNF studies recruited participants with MCI from clinical settings, who were consuming various psychotropic medications. Some of these medications, such as anti-depressants, have been reported to restore peripheral BDNF to normal levels in patients with MDD [23, 34] making this a major confounder in accurately measuring baseline BDNF levels. Furthermore, most of the extant studies were conducted in the Western hemisphere, with a lower representation of MCI cases in individuals of Asian ethnicity.

Different lab approaches have also been noted to cause high heterogeneity in the peripheral measurements of BDNF. Different sample types (plasma versus serum) used to quantify peripheral BDNF could provide vastly different insights. Platelets can adjust their release of BDNF in response to multiple external factors that include anti-depressant medications [35], infection, and inflammation. Thus, plasma prepared to be platelet free may represent a more reliable measurement of steady state BDNF in the peripheral circulation. Another confounding factor for measuring peripheral BDNF levels in MCI is that BDNF has two distinct forms, proand mature. Notably, they have opposite effects, with pro-BDNF promoting neuronal cell death [36] while mature BDNF promotes neuronal cell growth and survival $[19,36]$. However, many previous studies fail to differentiate between these two forms [25, 37]. Additionally, only two out of the six BDNF assays available selectively measured mature-BDNF, while the remaining assays combined the signals for both proBDNF and mature-BDNF [37]. This failure to differentiate between the forms of BDNF has been noted as another important factor skewing accurate measurements of BDNF in extant MCI studies, causing contradictory findings $[25,37]$.

To the best of our knowledge, the discriminative accuracies of plasma BDNF for MCI and different MCI subtypes have been largely unexamined. Apart from the neurotrophin hypothesis of cognitive impairment, with $\mathrm{BDNF}$ as one of the prominent biomarkers, there are inflammatory and stress hypotheses for the development of dementia [38, 39], suggesting that chronic low-grade inflammation and persistent stress increase the risk of developing cognitive impairment. In this regard, high-sensitivity C-reactive protein (hs-CRP) is a biomarker for low-grade chronic inflammation, whereas dehydroepiandrosterone sulfate (DHEA-S) is a biomarker for the hypothalamic-pituitary-adrenal axis (HPA), the primary physiological system regulating chronic stress. Although BDNF interacts with inflammatory and stress markers [40, 41], studies on plasma BDNF, hs-CRP and DHEA-S in MCI in the same study are scarce. This hypothesized neuroimmune-stress axis [42] could be evidenced by the presence of significant associations between peripheral BDNF, with hs-CRP and DHEA-S. Worthy of note is that, apart from MCI, these biomarkers have also been implicated in MDD and GAD [43-47]. In addition, adults with cerebral palsy (CP) whom often have comorbid MCI, have similarly dysregulated biomarker levels [48], particularly similar hs-CRP level and lower plasma BDNF than MCI, hence making it even more imperative to control for the clinical and laboratory heterogeneity. Considering cases with co-morbid MDD, $\mathrm{GAD}$, and $\mathrm{CP}$ will allow a deeper understanding of the utility of these biomarkers in discriminating MCI from cognitive healthy aging. In addition, associations between BDNF and cognitive function are rarely examined, hence investigating these associations will further our understanding on the roles of peripheral BDNF in modulating various cognitive functions impacted in MCI.

To address the gaps in knowledge outlined above, we compared two cohorts, healthy control (HC) and MCI, which had been controlled for the clinical and lab variability issues shared. This pilot study had four aims. First, we aimed to determine if the three biomarkers of interest, namely plasma BDNF, hs-CRP, and DHEA-S, have significantly different levels in participants with MCI compared to HC. Second, we aimed to determine the discriminative accuracies, sensitivities and specificities of these biomarkers in identifying MCI, in a series of sensitivity analyses that excluded those comorbid with probable MDD, GAD, and CP [33]. Third, we investigated the associations, or the lack thereof, between: a) BDNF and hs-CRP/ DHEA-S, and b) the biomarkers and detailed neurocognitive tests. Lastly, as exploratory analyses, we separately investigated the levels and the discriminative accuracies of these three biomarkers in $\mathrm{CP}$, probable $\mathrm{MDD}$, and probable $\mathrm{GAD}$, compared to $\mathrm{HC}$.

\section{RESULTS}

\section{Demographics}

Table 1 summarizes the demographic characteristics of the study participants. We recruited a total of 160 participants, mean age $=71.18, \mathrm{SD}=5.66$ (MCI cohort, $\mathrm{n}=40)$, mean age $=66.95, \mathrm{SD}=4.29$ (HC cohort, $\mathrm{n}=56$ ), and mean age $=25, \mathrm{SD}=5.39 \quad(\mathrm{CP}$ cohort, $\mathrm{n}=64$; $\mathrm{P}<0.001)$. Most of the participants were female in both MCI and HC cohorts [MCI cohort $\mathrm{n}=28$ (70\%); HC cohort, $\mathrm{n}=45(80.40 \%)$ ], while relatively balanced sex in the CP cohort [ $\mathrm{n}=29(45.3 \%) ;<0.001]$. Notably, the years of formal education differed significantly between the cohorts, as did the total number of chronic diseases 
Table 1. Demographic characteristics.

\begin{tabular}{|c|c|c|c|c|}
\hline \multirow{2}{*}{ Demographic characteristics } & \multicolumn{3}{|c|}{ Mean \pm SD or n $(\%)$} & \multirow{2}{*}{$P$-values } \\
\hline & MCI $(n=40)$ & HC $(n=56)$ & $C P(n=64)$ & \\
\hline Age (in years) & $71.18 \pm 5.66$ & $66.95 \pm 4.29$ & $25 \pm 5.39$ & $<0.001 * * *$ \\
\hline \multicolumn{5}{|l|}{ Sex } \\
\hline Female & $28(70)$ & $45(80.40)$ & $29(45.3)$ & \multirow{2}{*}{$<0.001 * * *$} \\
\hline Male & $12(30)$ & $11(19.60)$ & $35(54.7)$ & \\
\hline Years of formal education & $4.33 \pm 4.76$ & $7.13 \pm 3.66$ & $13.45 \pm 2.12$ & $<0.001 * * *$ \\
\hline BMI & $24.78 \pm 4.13$ & $24.03 \pm 3.58$ & $23.95 \pm 5.19$ & 0.634 \\
\hline Total number of chronic diseases & $2.88 \pm 1.53$ & $1.91 \pm 1.47$ & - & - \\
\hline Plasma Log BDNF & $3.19 \pm 0.37$ & $2.66 \pm 0.27$ & $2.07 \pm 0.52$ & $<0.001 * * *$ \\
\hline Plasma Log hs-CRP & $0.21 \pm 0.45$ & $-0.06 \pm 0.43$ & $-0.05 \pm 0.60$ & 0.018* \\
\hline Plasma Log DHEA-S & $2.44 \pm 0.52$ & $2.39 \pm 0.44$ & - & - \\
\hline MCI subtypes- amnestic MCI & $18(45)$ & - & - & - \\
\hline Non-amnestic MCI & $22(55)$ & - & - & - \\
\hline Probable MDD-Yes & $11(27.5)$ & $3(5.4)$ & $10(15.9)$ & $0.010 *$ \\
\hline No & $29(72.5)$ & $53(94.6)$ & $53(84.1)$ & \\
\hline Probable GAD-Yes & $5(12.5)$ & $5(8.9)$ & $28(44.4)$ & $<0.001 * * *$ \\
\hline No & $35(87.5)$ & $51(91.1)$ & $35(55.6)$ & \\
\hline
\end{tabular}

Notes: $\mathrm{MCl}$, mild cognitive impairment; $\mathrm{HC}$, healthy control; $\mathrm{CP}$, cerebral palsy; $\mathrm{n}$, Number; $\mathrm{SD}$, Standard deviation; $\mathrm{BMI}$, body-mass index; BDNF, Brain-derived neurotrophic factor; hs-CRP, High-sensitivity C-reactive Protein; DHEA-S, Dehydroepiandrosterone sulfate; NCA, neurocognitive tests; MDD, major depressive disorder; GAD, generalized anxiety disorder; NA, not applicable; ${ }^{*}$ indicates $\mathrm{p}<0.05, * * *$ indicates $\mathrm{p}<0.01$, and ${ }^{* * *}$ indicates $\mathrm{p}<0.001 ;-=$ not available in the dataset.

and the proportion of cases with probable MDD and GAD. No significant differences were observed for BMI and plasma log DHEA-S.

\section{Plasma BDNF and hs-CRP, but not DHEA-S, were elevated in MCI versus $\mathrm{HC}$}

As shown in Figure 1A and Table 2A, plasma BDNF levels were significantly increased in MCI $(n=40$, $3.19 \pm 0.37 \mathrm{pg} / \mathrm{mL})$, compared to $\mathrm{HC} \quad(\mathrm{n}=120$, $2.34 \pm 0.51 \mathrm{pg} / \mathrm{mL}, \mathrm{p}<0.001)$. This effect remained once participants with $\mathrm{CP}$, probable MDD and probable GAD were excluded from the analyses, resulting in an MCI population of $(\mathrm{n}=28,3.16 \pm 0.40 \mathrm{pg} / \mathrm{mL})$ and $\mathrm{HC}(\mathrm{n}=48$, $2.65 \pm 0.28 \mathrm{pg} / \mathrm{mL}, \quad \mathrm{p}<0.001)$. Similarly, there were significantly increased plasma BDNF in both aMCI and non-aMCI (Table 2B, 2C). We further showed (Supplementary Table 1) that even after controlling for a range of other confounders, plasma BDNF remained significantly different in MCI compared to $\mathrm{HC}(\beta=0.47$, $95 \% \mathrm{CI}=0.32$ to $\left.0.62, \mathrm{p}<0.001, \mathrm{R}^{2}=0.44\right)$.

Plasma hs-CRP had similar findings as BDNF. Hs-CRP had significantly increased levels for all-cause MCI and non-aMCI. Plasma DHEA-S did not have significant difference across all the models.
High discriminative accuracies, sensitivities, and specificities of plasma BDNF for MCI and nonaMCI, including in sensitivity analyses removing cases with psychiatric co-morbidities

As displayed in Table 2A, 2B and Figure 2A, 2B, upon removing cases with $\mathrm{CP}$, probable MDD and GAD from the analyses, plasma BDNF showed good $(\mathrm{AUC}=0.84$, $95 \% \mathrm{CI}=0.74$ to $0.95, \quad \mathrm{p}<0.001)$ and excellent discriminative accuracy ( $\mathrm{AUC}=0.92,95 \% \mathrm{CI}=0.84$ to $1.00, \mathrm{p}<0.001)$ for all-cause $\mathrm{MCI}$ and non-amnestic MCI, respectively. Youden's Index-derived optimal log BDNF cut-off point for all-cause MCI was 2.990, with sensitivity $=72.5 \%$ and specificity $=89.3 \%$. Whereas for non-aMCI, the cut-off point was 3.134 , with sensitivity $=81.3 \%$ and specificity $=95.8 \%$. In addition, although the discriminative accuracy of BDNF for aMCI was comparatively lower, it still had good discriminative accuracy (AUC $=0.74,95 \% \mathrm{CI}=0.55$ to 0.92, $\mathrm{p}=0.012)($ Table 2C).

\section{Associations between plasma BDNF and hs-CRP, but not with DHEA-S}

To examine the presence of the proposed connections between the three physiological systems, we examined 
the associations between plasma BDNF and plasma hs-CRP or DHEA-S (Table 3). Bivariate association between plasma hs-CRP and BDNF were positively and significantly associated, with a higher level of plasma BDNF associated significantly with a higher level of plasma hs-CRP ( $\beta=0.27,95 \% \mathrm{CI}=0.05$ to $0.49, \mathrm{p}=0.018$ ). However, the association was attenuated to become not significant (model 3: $\beta=0.16,95 \% \mathrm{CI}=-0.07$ to 0.39 , $\mathrm{p}=0.168$ ), when the covariate BMI was added. BDNF had no significant association with DHEA-S, even at the bivariate level, and this observation persisted through the subsequent models ( $>00.05$; Table 3 ).
Significant associations between plasma BDNF and multiple neurocognitive domains

In Table 4, we showed that higher plasma BDNF was significantly associated with lower cognitive test scores representing multiple cognitive domains, including Forward Digit Span $(\beta=-1.17,95 \% \mathrm{CI}=-2.04$ to $-0.31, p=0.009)$, Backward Digit Span $(\beta=-1.13$, $95 \% \mathrm{CI}=-1.83$ to $-0.42, \mathrm{p}=0.002)$, Block Design Test $(\beta=-4.86,95 \% \mathrm{CI}=-7.63$ to $-2.10, \mathrm{p}=0.001)$, and Semantic Fluency (Animal Naming) Test $(\beta=-1.76$, $95 \% \mathrm{CI}=-2.99$ to $-0.54, \mathrm{p}=0.005)$. On the other hand,

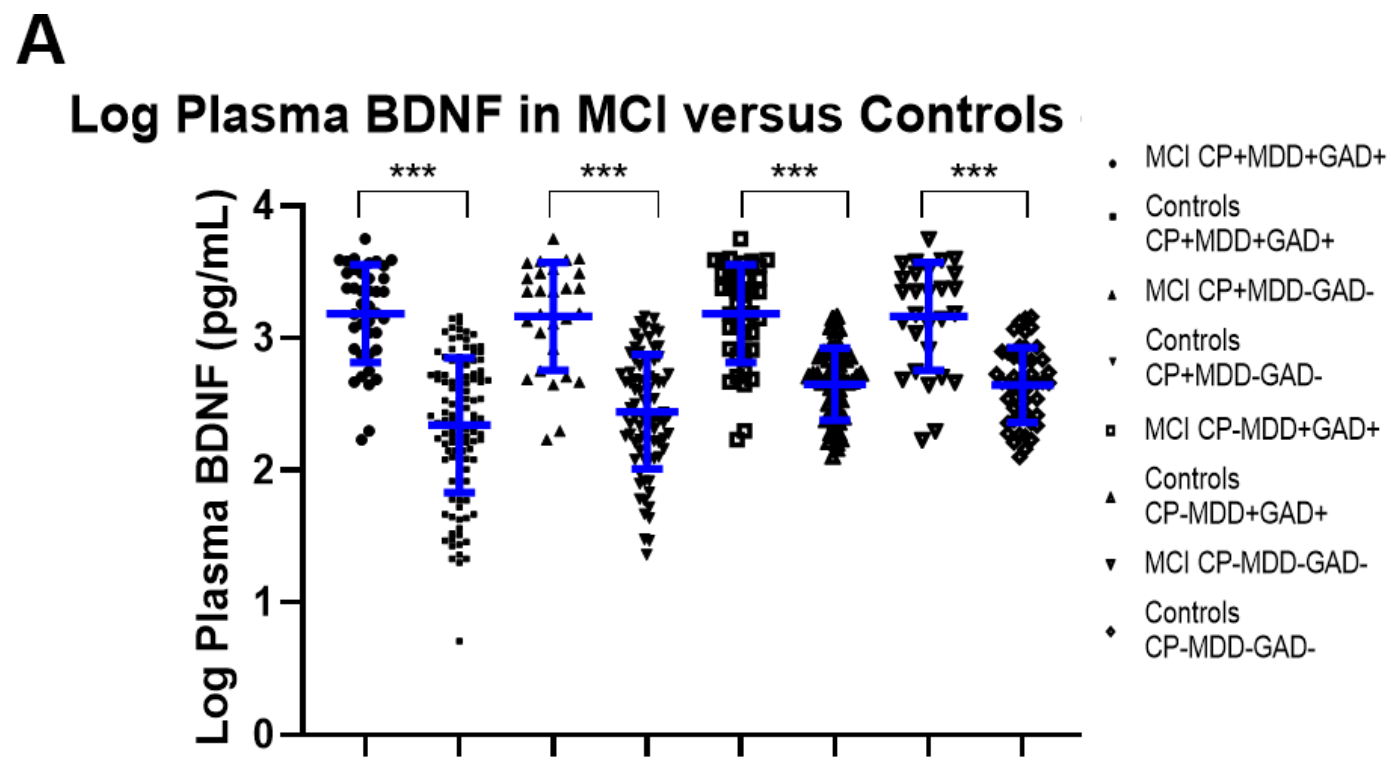

B

\section{Log Plasma BDNF in non-aMCl versus Controls}

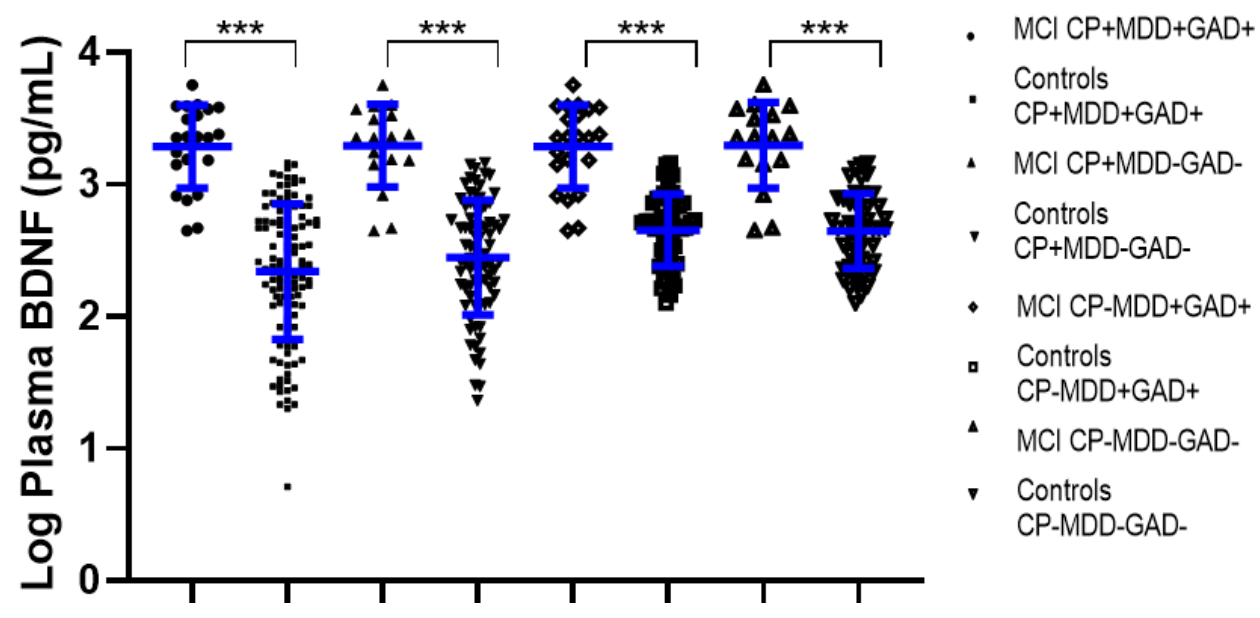

Figure 1. (A) Log Plasma BDNF levels in all-cause $\mathrm{MCl}$ cases compared to controls, with various sensitivity analyses including and removing co-morbidities. * indicates $\mathrm{p}<0.05, * * *$ indicates $\mathrm{p}<0.01$, and $* * *$ indicates $\mathrm{p}<0.001$. (B) Log Plasma BDNF levels in non-amnestic (non-a) MCI cases compared to controls, with various sensitivity analyses including and removing co-morbidities. ${ }^{*}$ indicates $p<0.05, * * *$ indicates $p<0.01$, and $* * *$ indicates $p<0.001$. 
Table 2A. Biomarker levels for each sub-group and their discriminative accuracies for all-cause $\mathrm{MCl}$.

\begin{tabular}{|c|c|c|c|c|c|c|c|c|c|c|c|}
\hline & \multirow{3}{*}{$\begin{array}{c}\text { Inclusion of } \\
\text { probable } \\
\text { MDD and } \\
\text { GAD? }\end{array}$} & \multirow{3}{*}{ Biomarkers } & \multicolumn{5}{|c|}{ Biomarker levels (compared to control) } & \multicolumn{4}{|c|}{ Discriminative accuracies } \\
\hline & & & \multicolumn{2}{|c|}{$\begin{array}{c}\text { Clinically } \\
\text { diagnosed MCI }\end{array}$} & \multicolumn{2}{|c|}{ Control } & \multirow[t]{2}{*}{ P-value } & \multirow[t]{2}{*}{ AUC } & \multirow[t]{2}{*}{ SE } & \multirow{2}{*}{$\begin{array}{c}95 \% \text { CI of } \\
\text { AUC }\end{array}$} & \multirow[t]{2}{*}{ P-value } \\
\hline & & & $\mathbf{n}$ & Mean (SD) & $\mathbf{n}$ & Mean (SD) & & & & & \\
\hline \multirow{3}{*}{$\mathrm{CP}$ cohort included } & \multirow[t]{2}{*}{ Included } & Log BDNF & 40 & $3.19(0.37)$ & 120 & $2.34(0.51)$ & $<0.001 * * *$ & 0.91 & 0.03 & 0.86 to 0.97 & $<0.001 * * *$ \\
\hline & & Log hs-CRP & 42 & $0.21(0.44)$ & 128 & $-0.05(0.52)$ & $0.004 * *$ & 0.65 & 0.05 & 0.56 to 0.74 & $0.005 * *$ \\
\hline & Excluded & Log BDNF & 28 & $3.16(0.41)$ & 80 & $2.45(0.43)$ & $<0.001 * * *$ & 0.88 & 0.04 & 0.81 to 0.96 & $<0.001 * * *$ \\
\hline \multirow{5}{*}{$\mathrm{CP}$ cohort excluded } & \multirow[t]{3}{*}{ Included } & Log BDNF & 40 & $3.19(0.37)$ & 56 & $2.65(0.27)$ & $<0.001 * * *$ & 0.87 & 0.04 & 0.79 to 0.95 & $<0.001 * * *$ \\
\hline & & Log hs-CRP & 42 & $0.21(0.44)$ & 56 & $-0.06(0.43)$ & $0.003 * *$ & 0.65 & 0.06 & 0.54 to 0.76 & 0.012* \\
\hline & & Log DHEA-S & 42 & $2.46(0.53)$ & 56 & $2.39(0.44)$ & 0.440 & 0.50 & 0.06 & 0.37 to 0.62 & 0.947 \\
\hline & \multirow[t]{2}{*}{ Excluded } & Log BDNF & 28 & $3.16(0.40)$ & 48 & $2.65(0.28)$ & $<0.001 * * *$ & 0.84 & 0.05 & 0.74 to 0.95 & $<0.001 * * *$ \\
\hline & & Log hs-CRP & 30 & $0.21(0.44)$ & 48 & $-0.08(0.43)$ & $0.006 * *$ & 0.67 & 0.07 & 0.54 to 0.79 & $0.016 *$ \\
\hline
\end{tabular}

Table 2B. Biomarker levels for each sub-group and their discriminative accuracies for non-aMCl.

\begin{tabular}{|c|c|c|c|c|c|c|c|c|c|c|c|}
\hline & \multirow{3}{*}{$\begin{array}{c}\text { Inclusion of } \\
\text { probable } \\
\text { MDD and } \\
\text { GAD? }\end{array}$} & \multirow{3}{*}{ Biomarkers } & \multicolumn{5}{|c|}{ Biomarker levels (compared to control) } & \multicolumn{4}{|c|}{ Discriminative accuracies } \\
\hline & & & \multicolumn{2}{|c|}{$\begin{array}{c}\text { Clinically } \\
\text { diagnosed MCI }\end{array}$} & \multicolumn{2}{|c|}{ Control } & \multirow{2}{*}{ P-value } & \multirow[t]{2}{*}{ AUC } & \multirow[t]{2}{*}{ SE } & \multirow{2}{*}{$\begin{array}{c}95 \% \text { CI of } \\
\text { AUC }\end{array}$} & \multirow[t]{2}{*}{ P-value } \\
\hline & & & n & Mean (SD) & $\mathbf{n}$ & Mean (SD) & & & & & \\
\hline \multirow{3}{*}{$\mathrm{CP}$ cohort included } & \multirow[t]{2}{*}{ Included } & Log BDNF & 22 & $3.29(0.31)$ & 120 & $2.34(0.51)$ & $<0.001 * * *$ & 0.95 & 0.02 & 0.91 to 1.00 & $<0.001 * * *$ \\
\hline & & Log hs-CRP & 24 & $0.16(0.46)$ & 128 & $-0.05(0.52)$ & 0.064 & 0.61 & 0.06 & 0.49 to 0.74 & 0.094 \\
\hline & Excluded & Log BDNF & 16 & $3.29(0.32)$ & 80 & $2.45(0.43)$ & $<0.001 * * *$ & 0.94 & 0.03 & 0.88 to 1.00 & $<0.001 * * *$ \\
\hline \multirow{5}{*}{$\mathrm{CP}$ cohort excluded } & \multirow[t]{3}{*}{ Included } & Log BDNF & 22 & $3.29(0.31)$ & 56 & $2.65(0.27)$ & $<0.001 * * *$ & 0.92 & 0.04 & 0.85 to 1.00 & $<0.001 * * *$ \\
\hline & & Log hs-CRP & 24 & $1.56(0.46)$ & 56 & $-0.06(0.43)$ & $0.046 *$ & 0.61 & 0.08 & 0.46 to 0.76 & 0.131 \\
\hline & & Log DHEA-S & 24 & $2.33(0.53)$ & 56 & $2.39(0.44)$ & 0.631 & 0.39 & 0.08 & 0.24 to 0.54 & 0.128 \\
\hline & \multirow[t]{2}{*}{ Excluded } & Log BDNF & 16 & $3.29(0.32)$ & 48 & $2.65(0.28)$ & $<0.001 * * *$ & 0.92 & 0.04 & 0.84 to 1.00 & $<0.001 * * *$ \\
\hline & & Log hs-CRP & 18 & $0.21(0.49)$ & 48 & $-0.08(0.43)$ & $0.022 *$ & 0.65 & 0.09 & 0.48 to 0.82 & 0.067 \\
\hline
\end{tabular}

Footnote: $\mathrm{aMCl}$ cases $(n=18)$ were excluded from all the analyses presented in this table.

Table 2C. Biomarker levels for each sub-group and their discriminative accuracies for aMCI.

\begin{tabular}{|c|c|c|c|c|c|c|c|c|c|c|c|}
\hline & \multirow{2}{*}{$\begin{array}{l}\text { Inclusion of } \\
\text { probable } \\
\text { MDD and } \\
\text { GAD? }\end{array}$} & \multirow[b]{2}{*}{ Biomarkers } & \multicolumn{5}{|c|}{ Biomarker levels (compared to control) } & \multicolumn{4}{|c|}{ Discriminative accuracies } \\
\hline & & & \multicolumn{2}{|c|}{$\begin{array}{c}\text { Clinically } \\
\text { diagnosed MCI }\end{array}$} & \multicolumn{2}{|c|}{ Control } & P-value & AUC & SE & $\begin{array}{c}95 \% \text { CI of } \\
\text { AUC }\end{array}$ & P-value \\
\hline \multirow{3}{*}{$\mathrm{CP}$ cohort included } & \multirow[t]{2}{*}{ Included } & Log BDNF & 18 & $3.06(0.41)$ & 120 & $2.34(0.51)$ & $<0.001 * * *$ & 0.87 & 0.05 & 0.78 to 0.96 & $<0.001 * * *$ \\
\hline & & Log hs-CRP & 18 & $0.28(0.41)$ & 128 & $-0.05(0.52)$ & 0.011* & 0.69 & 0.06 & 0.58 to 0.80 & $0.010 *$ \\
\hline & Excluded & Log BDNF & 12 & $2.99(0.45)$ & 80 & $2.45(0.43)$ & $<0.001 * * *$ & 0.80 & 0.07 & 0.66 to 0.95 & $<0.001 * * *$ \\
\hline \multirow{5}{*}{ CP cohort excluded } & \multirow[t]{3}{*}{ Included } & $\log$ BDNF & 18 & $3.06(0.41)$ & 56 & $2.65(0.27)$ & $<0.001 * * *$ & 0.80 & 0.07 & 0.66 to 0.94 & $<0.001 * * *$ \\
\hline & & Log hs-CRP & 18 & $0.28(0.41)$ & 56 & $-0.06(0.43)$ & $0.005^{* *}$ & 0.70 & 0.07 & 0.57 to 0.83 & 0.011* \\
\hline & & Log DHEA-S & 18 & $2.64(0.49)$ & 56 & $2.39(0.44)$ & 0.044 & 0.63 & 0.08 & 0.46 to 0.79 & 0.107 \\
\hline & \multirow[t]{2}{*}{ Excluded } & Log BDNF & 12 & $2.99(0.45)$ & 48 & $2.65(0.28)$ & $0.026^{*}$ & 0.74 & 0.10 & 0.55 to 0.92 & $0.012 *$ \\
\hline & & Log hs-CRP & 12 & $0.20(0.37)$ & 48 & $-0.08(0.43)$ & 0.045 & 0.68 & 0.08 & 0.52 to 0.84 & 0.052 \\
\hline
\end{tabular}

Footnote: non-aMCl cases $(n=22)$ were excluded from all the analyses presented in this table. 

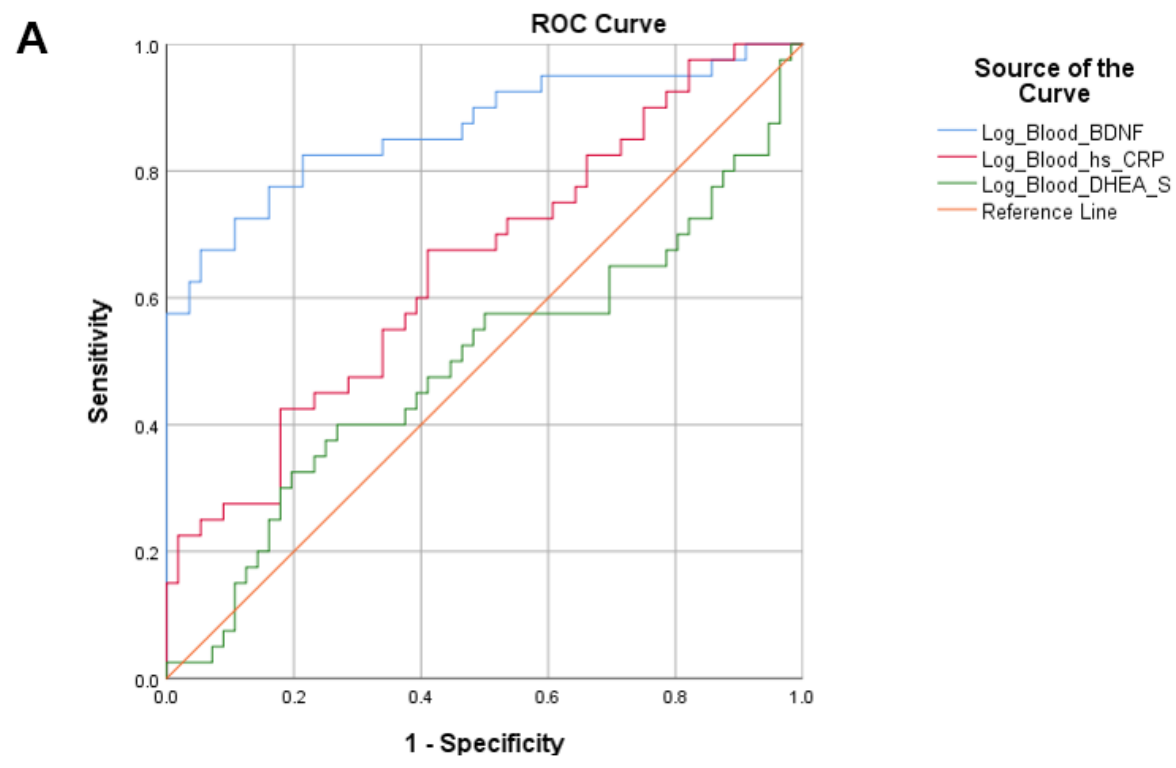

\begin{tabular}{|l|l|l|l|l|l|}
\hline Biomarkers & AUCs & $\begin{array}{l}\text { Youden's } \\
\text { Index }\end{array}$ & $\begin{array}{l}\text { Youden's Index-derived optimal } \\
\text { biomarker cut-off points }\end{array}$ & $\begin{array}{l}\text { Sensitivity } \\
(\%)\end{array}$ & $\begin{array}{l}\text { Specificity } \\
(\%)\end{array}$ \\
\hline Log BDNF & $\mathbf{0 . 8 4}$ & $\mathbf{0 . 6 1 8}$ & $\mathbf{2 . 9 9 0}$ & 72.5 & 89.3 \\
\hline Log hs-CRP & $\mathbf{0 . 6 7}$ & $\mathbf{0 . 2 6 4}$ & $\mathbf{0 . 0 2 9}$ & 67.5 & 41.1 \\
\hline Log DHEA-S & $\mathbf{0 . 4 3}$ & $\mathbf{0 . 1 3 2}$ & $\mathbf{2 . 5 0 4}$ & $\mathbf{4 0}$ & $\mathbf{7 3 . 2}$ \\
\hline
\end{tabular}

B
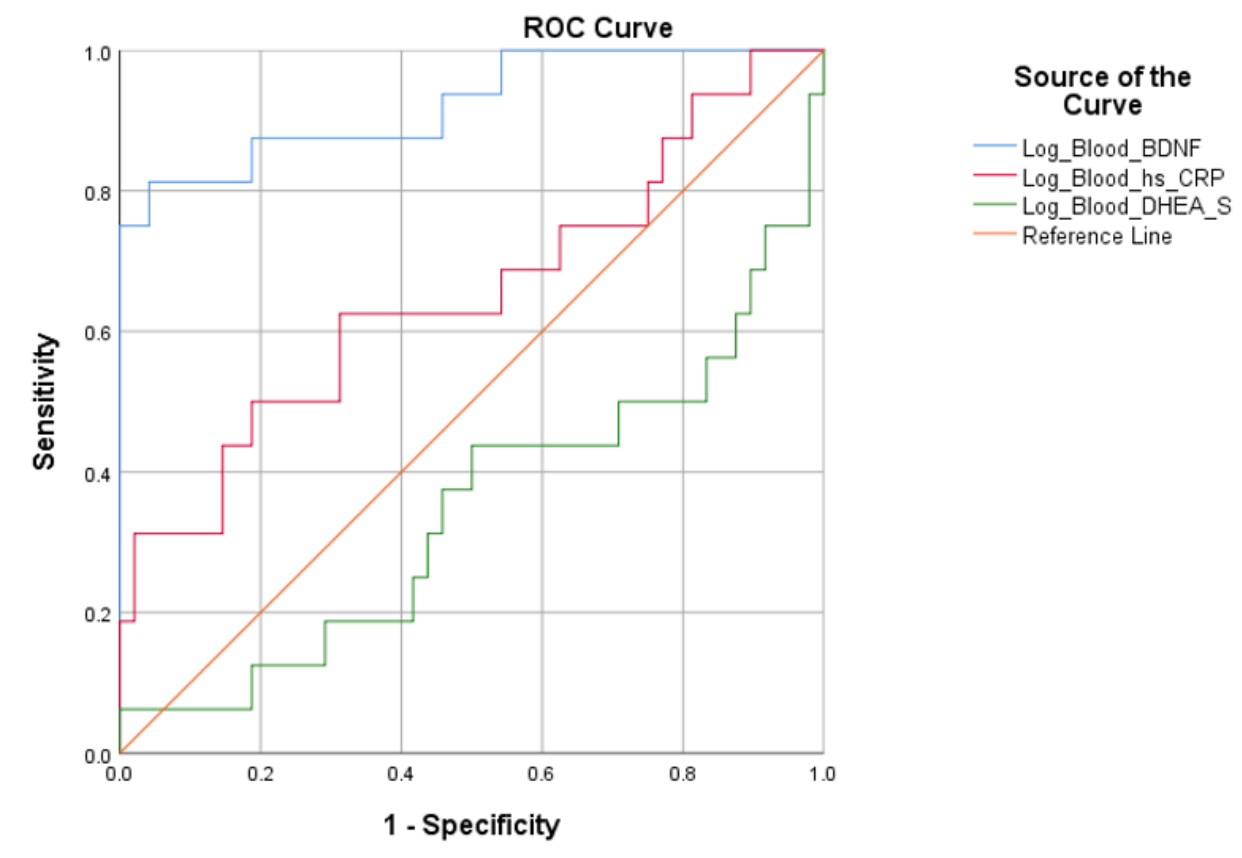

\begin{tabular}{|l|l|l|l|l|l|}
\hline Biomarkers & AUCs & $\begin{array}{l}\text { Youden's } \\
\text { Index }\end{array}$ & $\begin{array}{l}\text { Youden's Index-derived optimal } \\
\text { biomarker cut-off points }\end{array}$ & $\begin{array}{l}\text { Sensitivity } \\
(\%)\end{array}$ & $\begin{array}{l}\text { Specificity } \\
(\%)\end{array}$ \\
\hline Log BDNF & 0.92 & 0.771 & 3.134 & 81.3 & 95.8 \\
\hline Log hs-CRP & 0.65 & 0.312 & 0.230 & 50 & 81.2 \\
\hline Log DHEA-S & 0.35 & 0.063 & 3.768 & 6.3 & 100 \\
\hline
\end{tabular}

Figure 2. (A) ROC curves of discriminative accuracies of BDNF, hs-CRP and DHEA-S for all-cause $\mathrm{MCl}$ cases for the analysis removing all comorbidities. (B) ROC curves of discriminative accuracies of BDNF, hs-CRP and DHEA-S for non-amnestic MCl for the analysis removing all comorbidities. 
Table 3. Associations between plasma BDNF with hs-CRP and DHEA-S.

\begin{tabular}{lcccc}
\hline \multirow{2}{*}{ Biomarkers } & Models & & & \\
\cline { 3 - 5 } & 1 & $0.27(0.05$ to 0.49$)$ & $\mathbf{0 . 0 1 8} *$ & 0.06 \\
\hline \multirow{2}{*}{ Log Hs-CRP } & 2 & $0.26(0.02$ to 0.50$)$ & $\mathbf{0 . 0 3 8} *$ & 0.07 \\
& $3^{\#}$ & $0.16(-0.07$ to 0.39$)$ & 0.168 & 0.24 \\
& 4 & $0.15(-0.08$ to 0.38$)$ & 0.186 & 0.26 \\
Log DHEA-S & 1 & $0.07(-0.18$ to 0.31$)$ & 0.581 & 0.003 \\
& 2 & $0.04(-0.13$ to 0.21$)$ & 0.657 & 0.60 \\
& 3 & $0.03(-0.14$ to 0.21$)$ & 0.700 & 0.60 \\
& 4 & $0.01(-0.16$ to 0.19$)$ & 0.894 & 0.62 \\
\hline
\end{tabular}

Footnotes: Independent variable in the model was Log BDNF, Brain-derived neurotrophic factor; dependent variables: Hs-CRP, High-sensitivity C-reactive Protein; DHEA-S, Dehydroepiandrosterone sulfate.

$95 \% \mathrm{Cl}, 95 \%$ confidence interval; * indicates $\mathrm{p}<0.05$; \# indicates the significant covariate in model 3 was body-mass index (BMI).

Model 1: bivariate association.

Model 2: added age, sex, years of formal education.

Model 3: added body-mass index and the total number of chronic diseases.

Model 4: added two other biomarkers.

plasma BDNF was significantly associated with higher scores of Colour Trail Test I $(\beta=23.77,95 \% \mathrm{CI}=5.70$ to 41.85, $\mathrm{p}=0.011)$ and Colour Trail Test II $(\beta=29.77$, $95 \% \mathrm{CI}=11.32$ to $48.22, \mathrm{p}=0.002)$. Notably, plasma BDNF alone accounted for $19-24 \%\left(\mathrm{R}^{2}=0.19\right.$ to 0.24$)$ of the variance across different neurocognitive tests (model 1 of each respective test). On the contrary, plasma hsCRP and DHEA-S had no significant associations with the neurocognitive tests (data not shown).

\section{Exploratory analyses - levels and discriminative accuracies of plasma BDNF, hs-CRP, and DHEA-S for $\mathrm{CP}$, probable MDD, and probable GAD}

For the co-morbidities, sensitivity analyses removing the co-morbidities showed a significantly higher level of hs-CRP in probable MDD $(\mathrm{n}=3,0.44 \pm 0.16 \mathrm{ng} / \mathrm{mL})$, compared to $\mathrm{HC}(\mathrm{n}=53,-0.09 \pm 0.43 \mathrm{ng} / \mathrm{mL}, \mathrm{p}=0.036)$ (Supplementary Table 2A), and borderline higher BDNF. DHEA-S seemed to be significantly lower in probable GAD cases $(\mathrm{n}=5, \quad 2.01 \pm 0.31 \mathrm{ng} / \mathrm{mL})$, compared to $\mathrm{HC}(\mathrm{n}=51,2.42 \pm 0.44 \mathrm{ng} / \mathrm{mL}, \mathrm{p}=0.047)$ (Supplementary Table 2B). CP had significantly decreased plasma BDNF (Supplementary Table 2C) $(\mathrm{n}=32,2.15 \pm 0.45 \mathrm{pg} / \mathrm{mL}$, compared to $\mathrm{HC} \quad(\mathrm{n}=48$, $2.65 \pm 0.28, \mathrm{p}<0.001)$.

Shown in Table 2A, 2B and Figure 2A, 2B were discriminative accuracies of the three biomarkers for probable MDD, GAD, and CP separately (Supplementary Tables 2A-2C, respectively). Although significantly lower BDNF had great discriminative accuracies for $\mathrm{CP}$ (AUC $=0.82,95 \% \mathrm{CI}=0.72$ to $0.93, \mathrm{p}=0.05$ ), plasma BDNF had a comparatively much poorer discriminative accuracy for both MDD and GAD (AUC $=0.62,95 \%$ $\mathrm{CI}=0.49$ to $0.75, \mathrm{p}=0.478)$ and $(\mathrm{AUC}=0.47,95 \% \mathrm{CI}=0.22$ to $0.72, \mathrm{p}=0.829)$, respectively. Furthermore, elevated plasma hs-CRP had excellent discriminative accuracy for probable MDD (AUC $=0.91,95 \% \mathrm{CI}=0.81$ to 1.00 , $\mathrm{p}=0.019)$ (Supplementary Table 2A).

\section{DISCUSSION}

Addressing the clinical and laboratory heterogeneity causal of the contradictory evidence present in the literature, we found plasma BDNF to be significantly higher in MCI, compared to HC. Furthermore, elevated plasma BDNF had great discriminative accuracy for MCI, particularly excellent discriminative accuracy for non-aMCI. However, its discriminative accuracy for aMCI was poorer compared to those of total MCI and non-aMCI. These findings remained unchanged upon performing sensitivity analyses that excluded cases with co-morbid MDD and GAD, and sensitivity analyses with $\mathrm{CP}$. Furthermore, regression models associating plasma BDNF and hs-CRP further support the presence of a neurotrophin-inflammation axis that is mainly modulated by BMI. Lastly, presence of significant associations with multiple neurocognitive tests also support BDNF as a modulator of several cognitive functions. Although plasma hs-CRP was significantly elevated in MCI, it had relatively poor discriminative accuracy, while 
Table 4. Associations between plasma BDNF with multiple detailed neurocognitive tests.

\begin{tabular}{|c|c|c|c|c|}
\hline Detailed neurocognitive tests & Models & $\beta(95 \%$ CI $)$ & $P$-value & $R^{2}$ \\
\hline \multirow{4}{*}{ Forward Digit Span } & 1 & $-1.86(-2.66$ to -1.05$)$ & $<0.001 * * *$ & 0.19 \\
\hline & 2 & $-1.33(-2.15$ to -0.51$)$ & $\mathbf{0 . 0 0 2} * *$ & 0.31 \\
\hline & 3 & $-1.22(-2.06$ to -0.38$)$ & $0.005 * *$ & 0.33 \\
\hline & 4 & $-1.17(-2.04$ to -0.31$)$ & $0.009 * *$ & 0.33 \\
\hline \multirow{4}{*}{ Backward Digit Span } & 1 & $-1.85(-2.54$ to -1.17$)$ & $<0.001 * * *$ & 0.24 \\
\hline & 2 & $-1.24(-1.91$ to -0.56$)$ & $<0.001 * * *$ & 0.39 \\
\hline & 3 & $-1.18(-1.88$ to -0.47$)$ & $0.001 * *$ & 0.40 \\
\hline & 4 & $-1.13(-1.83$ to -0.42$)$ & $0.002 * *$ & 0.43 \\
\hline \multirow{4}{*}{ RAVLT Delayed Recall Test } & 1 & $-1.00(-2.23$ to 0.24$)$ & 0.11 & 0.03 \\
\hline & 2 & $-0.36(-1.57$ to 0.86$)$ & 0.56 & 0.22 \\
\hline & 3 & $-0.04(-1.28$ to 1.20$)$ & 0.95 & 0.26 \\
\hline & 4 & $0.11(-1.15$ to 1.37$)$ & 0.87 & 0.28 \\
\hline \multirow{4}{*}{$\begin{array}{l}\text { RAVLT Delayed Recognition } \\
\text { Test }\end{array}$} & 1 & $-0.40(-1.14$ to 0.35$)$ & 0.29 & 0.01 \\
\hline & 2 & $0.02(-0.75$ to 0.78$)$ & 0.97 & 0.16 \\
\hline & 3 & $0.28(-0.48$ to 1.04$)$ & 0.47 & 0.23 \\
\hline & 4 & $0.40(-0.35$ to 1.16$)$ & 0.29 & 0.28 \\
\hline \multirow{4}{*}{ Colour Trail Test I } & 1 & $45.18(26.55$ to 63.80$)$ & $<0.001 * * *$ & 0.20 \\
\hline & 2 & $26.75(9.36$ to 44.13$)$ & $0.003 * *$ & 0.43 \\
\hline & 3 & $23.16(5.37$ to 40.96$)$ & $0.011 *$ & 0.45 \\
\hline & 4 & 23.77 (5.70 to 41.85$)$ & 0.011* & 0.47 \\
\hline \multirow{4}{*}{ Colour Trail Test II } & 1 & $48.95(30.71$ to 67.19$)$ & $<0.001 * * *$ & 0.24 \\
\hline & 2 & $31.97(14.53$ to 49.40$)$ & $<0.001 * * *$ & 0.43 \\
\hline & 3 & $30.46(12.33$ to 48.59$)$ & $0.001 * *$ & 0.43 \\
\hline & 4 & 29.77 (11.32 to 48.22$)$ & $0.002 * *$ & 0.45 \\
\hline \multirow{4}{*}{ Block Design Test } & 1 & $-7.50(-10.26$ to -4.73$)$ & $<0.001 * * *$ & 0.24 \\
\hline & 2 & $-5.40(-8.05$ to -2.75$)$ & $<0.001 * * *$ & 0.43 \\
\hline & 3 & $-5.07(-7.80$ to -2.35$)$ & $<0.001 * * *$ & 0.45 \\
\hline & 4 & $-4.86(-7.63$ to -2.10$)$ & $0.001 * *$ & 0.46 \\
\hline \multirow{4}{*}{$\begin{array}{l}\text { Semantic Fluency (Animal } \\
\text { Naming) Test }\end{array}$} & 1 & $-3.19(-4.37$ to -2.00$)$ & $<0.001 * * *$ & 0.24 \\
\hline & 2 & $-2.27(-3.48$ to -1.06$)$ & $<0.001 * * *$ & 0.35 \\
\hline & 3 & $-2.03(-3.27$ to -0.80$)$ & $0.001 * *$ & 0.38 \\
\hline & 4 & $-1.76(-2.99$ to -0.54$)$ & $0.005 * *$ & 0.42 \\
\hline
\end{tabular}

Footnotes: Independent variable in the model was Log BDNF, Brain-derived neurotrophic factor; dependent variables, detailed neurocognitive tests; RAVLT, The Rey Auditory Verbal Learning Test. $95 \% \mathrm{Cl}, 95 \%$ confidence interval; * indicates $\mathrm{p}<0.05, * * *$ indicates $\mathrm{p}<0.01$, and $* * *$ indicates $\mathrm{p}<0.001$. Model 1: bivariate association.

Model 2: added age, sex, years of formal education.

Model 3: added body-mass index and the total number of chronic diseases.

Model 4: added two other biomarkers.

DHEA-S did not show significant difference and had poor discriminative accuracy for MCI. Taken together, in the context of four neurological and psychiatric conditions, plasma BDNF, but not hs-CRP nor DHEA$\mathrm{S}$, appears to be a good and excellent biomarker to discriminate MCI and non-aMCI, respectively. Given plasma BDNF's increased levels in MCI, along with its positive association with hs-CRP, and inverse associations with multiple neurocognitive domains, our data support the hypothesis that increased peripheral BDNF acts as a compensatory mechanism in the preclinical stage of dementia $[14,15]$. 
Compared to $\mathrm{HC}$, upon controlling for covariates, we found significantly higher plasma BDNF in MCI versus controls, regardless of whether we were assessing total or MCI sub-types. Furthermore, addressing four factors causing heterogeneity presents in previous studies [25, 28, 49], our pilot findings suggest that plasma BDNF had a high discriminative accuracy in differentiating MCI from HC. We also showed high discriminative accuracy, sensitivity and specificity for non-aMCI subtype, when more accurately measured peripheral BDNF was utilized. One previous study showed low and statistically insignificant discriminative accuracy of serum BDNF for MCI, which the author noted could have been caused by the high heterogeneity conferred by laboratory and clinical factors [50]. To our knowledge, only one previous study has examined the discriminative accuracy of plasma BDNF for aMCI. In that study, there was a lower level of plasma BDNF in aMCI compared to $\mathrm{HC}$. We propose that controlling for the heterogeneity-causing variables addressed in this study explains the discrepancy in these findings. Given the encouraging findings presented in this study, plasma BDNF's predictive accuracy for incident $\mathrm{MCI}$, especially non-aMCI cases, should be examined in future longitudinal studies.

Although neuroinflammation is known to affect several BDNF-related signalling pathways [51], its relationship with plasma BDNF in MCI remains largely unknown. In this study, we found a significant association between plasma BDNF and plasma hs-CRP. Hence, our findings provide empirical evidence that increased BDNF levels appeared to be associated with chronic low-grade inflammation in MCI. However, the association diminished upon further controlling for BMI, which appeared as a significant covariate. This finding concurs with the central role of hs-CRP as a marker of obesity and metabolic syndrome [52, 53], suggesting that although there could a neuro-immune axis and thus cross-talks in preclinical dementia, it is heavily dependent on and modulated by BMI. This finding highlights the importance of controlling for BMI when examining hs-CRP and BDNF in MCI. Surprisingly, we detected no significant associations between BDNF with DHEA-S, the HPA-axis mediator even at the bivariate level. Another prominent biomarker for the HPA-axis is cortisol, which has been shown to be elevated in MCI $[54,55]$, but was not examined in this study. Future work will incorporate this as a possible biomarker candidate. In addition, changes in the HPA-axis and clinical presentations in MCI could instead be mediated by alterations in glucocorticoid receptor sensitivity and transcriptional regulators, including NFkB, or FKBP-5 [56]. Taken together, these findings corroborate the neurotrophic and inflammatory hypotheses for CI, with no support for a direct role of DHEA-S.
We showed increased plasma BDNF levels were significantly associated with worse cognition across multiple cognitive domains impacted in MCI. These findings concur with the expression of $B D N F$ gene in various cortical areas corresponding to the cognitive functions associated with the detailed neurocognitive tests, including the cortex, hippocampus, and basal forebrain regions [17]. Furthermore, plasma BDNF alone accounted for $19-24 \%\left(\mathrm{R}^{2}=0.19\right.$ to 0.24$)$ of the variance explained in each of the cognitive domains, providing further support for its potentially prominent functions in modulating cognition in preclinical dementia. Taken together with increased BDNF levels in MCI and its high discriminative accuracy, sensitivity and specificity, coupled with positive association with the inflammatory marker (hs-CRP), these inverse associations with neurocognitive tests further support the hypothesis of increased BDNF as a compensatory mechanism to counter neuronal insults at the MCI stage. We postulate that there might be a dementia stagedependent function of plasma BDNF; At the MCI stage, although cognitive functions have generally deteriorated, plasma BDNF is upregulated as a compensatory mechanism and is thus associated with worse cognition. However, in the healthy aging and $\mathrm{AD}$ stages, BDNF likely serves a neuroprotective role and thus associates with better cognition, with higher peripheral BDNF levels protecting the older adults against dementia $[19,25]$. On the contrary, plasma hsCRP and DHEA-S had no significant associations with the neurocognitive tests. Future research needs to compare head-to-head plasma BDNF levels across the $\mathrm{AD}$ continuum and examine their differential associations with neurocognitive tests across different cognitive stages.

Lastly, as exploratory analyses, we also investigated the levels and the discriminative accuracies of the three biomarkers in three other co-morbid conditions and sensitivity analyses separately, namely probable MDD, probable GAD, and $\mathrm{CP}$. $\mathrm{CP}$ had significantly lower plasma BDNF levels and high discriminative accuracy, compared to controls who were older adults without MCI. This finding concurs with our previous findings reporting decreased peripheral $\mathrm{BDNF}$ in $\mathrm{CP}$ compared to MCI [48]. In this study, we showed that after addressing the factors causing heterogeneity in plasma $\mathrm{BDNF}$ and removing cases with co-morbidities, the findings still hold, suggesting relative independence of plasma BDNF from psychiatric co-morbidities in CP. On the other hand, only when cases with co-morbidities were removed did hs-CRP appeared significantly lower with a higher discriminative accuracy for identifying cases with probable MDD. These findings might shed light on the contradictory findings on hs-CRP in MDD $[45,57,58]$, as co-morbidities were frequently present 
in previous studies. Thus, these findings highlight the importance of considering co-morbidities when assessing hs-CRP in MDD. Due to the exploratory nature of the analyses for these three clinical conditions, future validations are necessary.

This study has several limitations. The main limitation was the relatively modest sample size and a nonmatched case control study design. Future studies should validate these findings in larger independent cohorts. Second, although it was not within the scope of this pilot study, future studies should include neuroimaging techniques, such as amyloid positron emission tomography (PET), to pathologically confirm MCI diagnosis. Having said that, our participants were clinically diagnosed with MCI and characterized using a robust two-step clinical diagnostic procedure (assessor assessment followed by a consensus panel meeting). Third, while we understand that blood biomarkers may not be as accurate a reflection of brain pathophysiology as CSF, the core intention of this study was to examine plasma biomarkers, as potentially less invasive fluid biomarkers for screening for MCI. Fourth, several covariates were not available in the datasets, such as $B D N F$ alleles, physical activity, social support, and homocysteine levels [19], leaving possible residual confounding. Our study also lacked a replication cohort. Thus, these encouraging pilot findings are preliminary and require further validation in other cohorts. It is worth noting that other similar studies with plasma BDNF measures in MCI and HC, which address all the concerns raised in this work, are not readily available to us. Finally, we did not have other diagnostic entities or canonical AD biomarkers to compare against BDNF. Due to the parsimonious involvements of BDNF in multiple psychiatric and neurological conditions, it is likely not a specific biomarker for a single condition, and perhaps more similar to neurofilament light (NfL) [59], is more likely a marker of neurodegeneration and neuroplasticity. Relatedly, previous works showed that despite having adequate statistical power, BDNF did not predict different neurodegenerative disease diagnostic statuses [60]. However, this may be again due to the lack of controlling for the confounders and variables we have discussed and addressed in this work.

In summary, this study addresses many well-established but often overlooked factors that cause high heterogeneity in BDNF levels. With that, we present this work as an important contribution to the body of knowledge supporting the compensatory roles of plasma BDNF in MCI, and show pilot data on the use of plasma BDNF to identify MCI from HC. In addition, by examining plasma BDNF in an Asian population, this study attempts to investigate the racial generalisability of current findings in the literature [25, 61], most of which are based primarily on Western-hemisphere populations. All participants were clinically well-characterised using well-established and validated instruments. Having multiple well-characterized clinical conditions in a single study conferred two main advantages: 1) we were able to perform multiple sensitivity analyses to mitigate the confounding effects of co-morbidities on the levels and discriminative accuracies of the biomarkers for MCI and therefore 2) we could provide pilot evidence comparing the levels and discriminative accuracies of the biomarkers in these four closely-related clinical conditions in a directly comparative manner. Further validation studies using longitudinal design and with larger sample sizes, as well as concurrently examining the levels of A $\beta-42$, p-Tau species, and NfL with plasma BDNF, could potentially support the use of plasma BDNF as a non-invasive biomarker for screening and triaging MCI diagnosis. Examinations of the relationship between BDNF in the cerebrospinal fluid (CSF) in future studies might also represent a promising avenue, allowing us to relate BDNF levels in plasma and CSF. These peripheral biomarkers might show negative correlations as is seen in increased salivary A $\beta-42[62$, 63] versus decreased CSF A $\beta-42$ [64] in MCI and AD. Clarifying these relationships may further bolster the increased level and compensatory mechanism of plasma BDNF in preclinical dementia.

\section{MATERIALS AND METHODS}

\section{Settings, study design, and participants}

\section{MCI cohort}

This study $[65,66]$ was approved by the National University of Singapore ethics committee, Institutional Review Board (NUS-IRB Reference No: B-14-110), and registered with the clinical trial database (https://clinicaltrials.gov/ct2/show/NCT02286791).

The inclusion criterion was fulfilling the operational criteria of MCI based on The Diagnostic and Statistical Manual of Mental Disorders, Fifth Edition (DSM-V) [67]. We excluded older adults with either dementia or normal aging, had a neurological or major psychiatric condition, had a terminal illness, had visual or hearing impairments, had upper and lower limb motor difficulties, and those who were participating in another intervention at the time of the screening. Final diagnoses of MCI were made during the study's consensus meetings chaired by a panel, consisting of at least two senior consultant-ranked psychiatrists, clinical scientists, and the trained assessors who administered the tests. Clinical diagnoses of cognitive status were made by adopting a robust two-step clinical diagnostic procedure (assessors' initial assessments followed by a consensus panel meeting) in the primary psychiatry research and 
teaching hospital in Singapore. All included participants were psychotropic medication naïve.

\section{Healthy control cohort}

This study [68-71] was approved by the National University of Singapore Institutional Review Board (NUS IRB-Reference Code: B-15-016) and registered with clinicaltrials.gov, with the identifier: NCT02495194 (https://clinicaltrials.gov/ct2/show/NCT02495194).

The participants needed to be community-dwelling older adults between 60 and 85 years old. They needed to score a minimum of 22 points on the Montreal Cognitive Assessment (MoCA) and retained the ability to provide informed consent. Older adults with major psychiatric disorders and those with a medical history of stroke, epilepsy, ischemic heart disease, heart failure, chronic obstructive pulmonary disease, cancer, liver failure, and thyroid disorder were excluded. Older adults with marked upper and lower limb motor difficulties, significant visual or hearing impairment were also excluded. Lastly, those undergoing any concurrent interventions or therapies, including consumption of psychotropic medication(s), were also excluded. The same consensus panel for diagnosing MCI assessed the final psychiatric diagnoses of these participants.

\section{Cerebral palsy cohort}

The CP cross-sectional study [48, 72] was approved by the Colorado Multiple Institutional Review Board (COMIRB Reference No: 14-0367), and registered with the clinical trial database (https://clinicaltrials.gov/ct2/ show/NCT02137005). The study was conducted at a clinical motion analysis laboratory at Children's Hospital Colorado. The laboratory has a specialized team of clinicians and researchers and is internationally accredited by the Commission for Motion Laboratory Accreditation (CMLA) (http://www.cmlainc.org/).

This is a cross-sectional case-control study with the three cohorts analysed. For all three cohorts, only the baseline data were analysed in this study. Detailed descriptions of each cohort, including criteria for clinical and probable diagnoses, can be found in the Supplementary Materials and in the respective publications.

\section{Measures}

\section{Biomarker measurements}

Blood sample collections

For all cohorts, blood collections were scheduled between 9:00 and 11:00 in the morning to minimize diurnal variations. The participants stopped consumption of foods after $10 \mathrm{pm}$ the night before venepuncture. The consumption of only water was advised. To reduce the confounding effects of stressors on the biomarkers, the participants were advised not to exercise or perform rigorous physical activities before the collections and not to rush to the research center if running late. Blood draw via venepuncture was performed by the research nurses on the day that the participants visited the research center. The blood samples were collected in K2-EDTA spray coated blood vacutainers (BD, New Jersey, USA). The blood samples were kept at $4^{\circ} \mathrm{C}$ for a maximum of three hours before being processed in the respective laboratories.

\section{Enzyme-linked immunosorbent assay (ELISA) measurements of plasma biomarkers}

To obtain plasma upon samples arriving at the lab, whole blood samples were centrifuged at $1650 \mathrm{~g}$ for $25 \mathrm{~min}$ at room temperature. Subsequently, plasma samples were bio-banked at $-80^{\circ} \mathrm{C}$ until study completion, after which all the samples were assayed in one batch. We employed commercially available ELISA kits to quantify the level of three plasma biomarkers, namely BDNF (Promega Corporation, Madison, WI, USA), hs-CRP (Tecan, Männedorf, Switzerland), and DHEA-S (CUSABIO, Houston, TX, USA). All experiments were performed as per instructions of respective manufacturers of the kits. For quantifying only the mature form of BDNF, we adhered to the protocol's instructions in pre-processing the samples before running ELISA. Specifically, to measure total BDNF using this assay, an acid treatment to the plasma sample is typically performed. However, for the purpose of this study to only measure free mature BDNF, the acid treatment procedures were skipped. Coefficient variations (CVs) of all the assays were $<10 \%$. All personnel who processed the samples and ran the ELISA were blinded to the diagnostic status of the participants.

\section{Neurocognitive tests}

Cognitive functions were examined using neurocognitive tests that have been validated to have good content validity and psychometric properties internationally and in the local context [73]. Details of the tests can be found in Supplementary Table 3. Higher scores in all neurocognitive tests indicate higher cognitive functions, except for the colour trail tests I and II, where lower test scores indicate higher cognitive functions.

\section{Statistical analyses}

Informed by our previous systematic review and metaanalysis on this topic [25], a cohort size of 60 is capable of detecting statistically significant difference in peripheral BDNF levels, assuming a $20 \%$ difference, with a power of 0.80 and type-I error of 0.05 [74]. All 
measures were expressed as mean \pm standard deviation (SD) for continuous measures and as number (percentage) for categorical measures. The differences in variables were examined using Student's $t$-test, chisquare or Fisher's exact tests, as the data necessitated. The raw values of the biomarker measurements did not fulfil the normality assumption; therefore, the raw values of the biomarkers were log-transformed for subsequent analyses and were successfully normalized, based on dot plots, skewness, and kurtosis. On the other hand, the raw values of the detailed neurocognitive tests conformed to statistical normality and thus were not transformed. To address aim 1, we performed two sets of analyses: one without controlling for covariates and another using linear regression analyses. In linear regression analyses, using a bivariate model, we first associated a dummy variable representing $\mathrm{MCI}$ or $\mathrm{HC}$ cohort (independent variable) with biomarkers (dependent variables) separately. Subsequently, we controlled for covariates, including age, gender, and years of formal education in model 2 and further controlled for additional covariates, namely body-mass index (BMI) and the total number of chronic diseases in model 3. To investigate aim 2, we determined the discriminative accuracies of these biomarkers for MCI by employing concordance (C-) statistics, with area under the curve (AUC) values as indicators. An AUC of $\geq 0.9$ was considered excellent, $\geq$ 0.8 considered good, and $\geq 0.7$ considered fair [75]. Attempting to disentangle the confounding effects of the other three neurological and psychiatric conditions, namely $\mathrm{CP}$, probable MDD, and GAD, on the discriminative accuracies of biomarkers, we performed sensitivity analyses where: 1) all receiver operating characteristic curve (ROCs) were run excluding the $\mathrm{CP}$ cohort, and 2) all analyses were run excluding all cases with probable MDD and GAD and 3) permutations of the two. Additionally, for biomarkers with high AUCs for MCI, the Youden index $[J]$ was calculated balancing sensitivity and specificity, which provides indications on the performance of a biomarker at an optimal cut-off point. The Youden index $(J=$ sensitivity + specificity 1 ) has a maximum value of 1 (indicating a perfect test) and a minimum of 0 , which is when the test has no diagnostic value. Hence, a useful biomarker should have a Youden Index exceeding 0.5, and the higher the value the better [76]. In Figure 2A, 2B, we reported the Youden's Index, the index-derived optimal biomarker cut-off points, specificities, and sensitivities. To investigate aim 3(a), we ran linear regressions associating BDNF with hs-CRP/DHEA-S, using stepwise regression models with the same covariates indicated previously included in the models, with the additional model 4 further controlled for two other biomarkers. To examine aim 3(b), we ran a separate set of linear regression models to determine if there were significant associations between the bio- markers with the detailed neurocognitive tests, sequentially controlling for covariates. To examine aim 4, similar ROC analyses as were carried out for addressing aim 2 were performed. All analyses were performed using the Statistical Package for the Social Sciences (SPSS) Statistics for Windows, version 24.0 (IBM Corp., Armonk, NY, USA). Missing values were excluded case-wise for all analyses. ROC curves and dot plots were generated using SPSS and GraphPad Prism version 6 (GraphPad Software, San Diego, CA, USA), respectively. A two-tailed p-value of $<0.05$ was considered statistically significant. Due to the pilot nature of this study, we did not control for multiple testing $[77,78]$.

\section{Abbreviations}

MCI: mild cognitive impairment; AD: Alzheimer's disease; non-aMCI: non-amnestic-MCI; HPA: hypothalamic-pituitary-adrenal; MDD: have co-morbid major depressive disorder; GAD: generalized anxiety disorder; hs-CRP: C-reactive protein; DHEA-S: dehydroepiandrosterone sulfate; HPA: hypothalamicpituitary-adrenal axis; CP: cerebral palsy; HC: healthy control; SD: standard deviation; AUC: area under the curve; ROCs: receiver operating characteristic curves; SPSS: Statistical Package for the Social Sciences.

\section{AUTHOR CONTRIBUTIONS}

Conceptualization: T.K.S.N.; parent cohorts and methodology: T.K.S.N., C.C., A.T., E.H.K, R.M., J.C., P.C.H.; data curation: T.K.S.N., A.T.; data analyses: T.K.S.N.; data presentation: T.K.S.N.; writing (first draft): T.K.S.N; Critical inputs and revisions: T.K.S.N., C.C., A.T., J.C., P.C.H., R.M; project administration: T.K.S.N., A.T.; supervision: T.K.S.N., E.H.K, R.M., J.C., P.C.H.; Funding Acquisition: J.C., P.C.H., E.H.K, R.M. All authors have read and agreed to the published version of the manuscript.

\section{ACKNOWLEDGMENTS}

We are grateful to the participants of the three studies. We would also like to thank the staffs, the students and volunteers from NUS, A*STAR's SIgN, TaRA@JP, the staff and volunteers from the National Parks Board, Gardens by the Bay, Government of Singapore, Training and Research Academy at Jurong Point (TaRA@JP) and Presbyterian Community Services (PCS), SAGE counseling center, NUS MIND-BODY Interest Group, and NUS Mind-Science Center. We also gratefully acknowledge Anis Larbi, Crystal Tan, Esther Mok, Bernett Lee, and the lab members from A*STAR's Singapore Immunology Network (SIgN) for their assistance with biomarkers analyses. 


\section{CONFLICTS OF INTEREST}

The funders had no roles in the collection, analyses, or interpretation of data; in the writing of the manuscript, and in the decision to publish the results.

\section{FUNDING}

The MCI cohort was supported by the funding from the Mind-Science Center, National University of Singapore (N-177-000-005-001). The HC cohort was supported by funding from the National Parks Board, Government of Singapore (N-177-000-005-001) to the Mind-Science Center and the National University of Singapore. For the CPAT cohort, the authors wish to acknowledge the important contributions of the CPAT co-investigator team (Heather Baer, Amy Bodkin, Tim Boyd, Meghan Colip, Tatiana Oliveira, Tim Reistetter, David Robertson, and Pam Wilson), the CP team at Children's Hospital Colorado lead by Dr. Frank Chang, and the faculty/staff of CGMA. It was supported by grants from the National Institute on Disability, Independent Living, and Rehabilitation Research (NIDILRR \#H133G130200, NIDILRR \#90IF0055-01), in the Administration for Community Living (ACL) of the Department of Health and Human Services (HHS). Additional support was provided from the J. T. Tai and Company Foundation.

\section{REFERENCES}

1. Grundman $M$, Petersen RC, Ferris $S H$, Thomas RG, Aisen PS, Bennett DA, Foster NL, Jack CR Jr, Galasko DR, Doody R, Kaye J, Sano M, Mohs R, et al, and Alzheimer's Disease Cooperative Study. Mild cognitive impairment can be distinguished from Alzheimer disease and normal aging for clinical trials. Arch Neurol. 2004; 61:59-66.

https://doi.org/10.1001/archneur.61.1.59

PMID:14732621

2. Petersen RC. Mild cognitive impairment as a diagnostic entity. J Intern Med. 2004; 256:183-94.

https://doi.org/10.1111/j.1365-2796.2004.01388.x

PMID:15324362

3. Reisberg B, Gauthier S. Current evidence for subjective cognitive impairment ( $\mathrm{SCl}$ ) as the pre-mild cognitive impairment (MCl) stage of subsequently manifest Alzheimer's disease. Int Psychogeriatr. 2008; 20:1-16. https://doi.org/10.1017/S1041610207006412 PMID:18072981

4. Slikker W Jr. Biomarkers and their impact on precision medicine. Exp Biol Med (Maywood). 2018; 243:211-12.

https://doi.org/10.1177/1535370217733426

PMID:28927290
5. Sperling RA, Aisen PS, Beckett LA, Bennett DA, Craft S, Fagan AM, Iwatsubo T, Jack CR Jr, Kaye J, Montine TJ, Park DC, Reiman EM, Rowe CC, et al. Toward defining the preclinical stages of Alzheimer's disease: recommendations from the National Institute on Aging-Alzheimer's Association workgroups on diagnostic guidelines for Alzheimer's disease. Alzheimers Dement. 2011; 7:280-92.

https://doi.org/10.1016/i.jalz.2011.03.003 PMID:21514248

6. Albert MS, DeKosky ST, Dickson D, Dubois B, Feldman $H H$, Fox NC, Gamst A, Holtzman DM, Jagust WJ, Petersen RC, Snyder PJ, Carrillo MC, Thies B, Phelps CH. The diagnosis of mild cognitive impairment due to Alzheimer's disease: recommendations from the National Institute on Aging-Alzheimer's Association workgroups on diagnostic guidelines for Alzheimer's disease. Alzheimers Dement. 2011; 7:270-79. https://doi.org/10.1016/i.jalz.2011.03.008 PMID:21514249

7. Jack CR Jr, Bennett DA, Blennow K, Carrillo MC, Dunn B, Haeberlein SB, Holtzman DM, Jagust W, Jessen F, Karlawish J, Liu E, Molinuevo JL, Montine T, et al, and Contributors. NIA-AA Research Framework: Toward a biological definition of Alzheimer's disease. Alzheimers Dement. 2018; 14:535-62.

https://doi.org/10.1016/i.jalz.2018.02.018 PMID:29653606

8. Hu WT, Watts KD, Shaw LM, Howell JC, Trojanowski JQ, Basra S, Glass JD, Lah JJ, Levey AI. CSF beta-amyloid 142 - what are we measuring in Alzheimer's disease? Ann Clin TransI Neurol. 2015; 2:131-39.

https://doi.org/10.1002/acn3.160 PMID:25750918

9. Clark CM, Schneider JA, Bedell BJ, Beach TG, Bilker WB, Mintun MA, Pontecorvo MJ, Hefti F, Carpenter AP, Flitter ML, Krautkramer MJ, Kung HF, Coleman RE, et al, and AV45-A07 Study Group. Use of florbetapir-PET for imaging beta-amyloid pathology. JAMA. 2011; 305:275-83.

https://doi.org/10.1001/jama.2010.2008 PMID:21245183

10. Marquié $M$, Siao Tick Chong $M$, Antón-Fernández $A$, Verwer EE, Sáez-Calveras N, Meltzer AC, Ramanan P, Amaral AC, Gonzalez J, Normandin MD, Frosch MP, Gómez-Isla T. [F-18]-AV-1451 binding correlates with postmortem neurofibrillary tangle Braak staging. Acta Neuropathol. 2017; 134:619-28.

https://doi.org/10.1007/s00401-017-1740-8 PMID:28612291

11. Craig-Schapiro R, Perrin RJ, Roe CM, Xiong C, Carter D, Cairns NJ, Mintun MA, Peskind ER, Li G, Galasko DR, Clark CM, Quinn JF, D'Angelo G, et al. YKL-40: a novel 
prognostic fluid biomarker for preclinical Alzheimer's disease. Biol Psychiatry. 2010; 68:903-12. https://doi.org/10.1016/j.biopsych.2010.08.025 PMID:21035623

12. Hu WT, Chen-Plotkin A, Arnold SE, Grossman M, Clark $\mathrm{CM}$, Shaw LM, Pickering E, Kuhn M, Chen Y, McCluskey L, Elman L, Karlawish J, Hurtig HI, et al. Novel CSF biomarkers for Alzheimer's disease and mild cognitive impairment. Acta Neuropathol. 2010; 119:669-78. https://doi.org/10.1007/s00401-010-0667-0 PMID:20232070

13. Hu WT, Holtzman DM, Fagan AM, Shaw LM, Perrin R, Arnold SE, Grossman M, Xiong C, Craig-Schapiro R, Clark CM, Pickering E, Kuhn $M$, Chen $\mathrm{Y}$, et al, and Alzheimer's Disease Neuroimaging Initiative. Plasma multianalyte profiling in mild cognitive impairment and Alzheimer disease. Neurology. 2012; 79:897-905. https://doi.org/10.1212/WNL.0b013e318266fa70 PMID:22855860

14. Laske C, Stransky E, Leyhe T, Eschweiler GW, Wittorf A, Richartz E, Bartels M, Buchkremer G, Schott K. Stagedependent BDNF serum concentrations in Alzheimer's disease. J Neural Transm (Vienna). 2006; 113:1217-24. https://doi.org/10.1007/s00702-005-0397-y PMID:16362629

15. Angelucci F, Spalletta G, di Iulio F, Ciaramella A, Salani F, Colantoni L, Varsi AE, Gianni W, Sancesario G, Caltagirone $C$, Bossù P. Alzheimer's disease (AD) and Mild Cognitive Impairment (MCl) patients are characterized by increased BDNF serum levels. Curr Alzheimer Res. 2010; 7:15-20. https://doi.org/10.2174/156720510790274473 PMID:20205668

16. Acheson A, Conover JC, Fandl JP, DeChiara TM, Russell M, Thadani A, Squinto SP, Yancopoulos GD, Lindsay RM. A BDNF autocrine loop in adult sensory neurons prevents cell death. Nature. 1995; 374:450-53. https://doi.org/10.1038/374450a0 PMID:

17. Lu B, Nagappan G, Guan X, Nathan PJ, Wren P. BDNFbased synaptic repair as a disease-modifying strategy for neurodegenerative diseases. Nat Rev Neurosci. 2013; 14:401-16. https://doi.org/10.1038/nrn3505 PMID:23674053

18. Pan W, Banks WA, Fasold MB, Bluth J, Kastin AJ. Transport of brain-derived neurotrophic factor across the blood-brain barrier. Neuropharmacology. 1998; 37:1553-61.

https://doi.org/10.1016/s0028-3908(98)00141-5 PMID: $\underline{9886678}$

19. Weinstein G, Beiser AS, Choi SH, Preis SR, Chen TC, Vorgas D, Au R, Pikula A, Wolf PA, DeStefano AL, Vasan RS, Seshadri S. Serum brain-derived neurotrophic factor and the risk for dementia: the Framingham Heart Study. JAMA Neurol. 2014; 71:55-61.

https://doi.org/10.1001/jamaneurol.2013.4781 PMID:24276217

20. Rahmani F, Saghazadeh A, Rahmani M, Teixeira AL, Rezaei N, Aghamollaii V, Ardebili HE. Plasma levels of brain-derived neurotrophic factor in patients with Parkinson disease: A systematic review and metaanalysis. Brain Res. 2019; 1704:127-36. https://doi.org/10.1016/i.brainres.2018.10.006 PMID:30296429

21. Ferrer I, Goutan E, Marín C, Rey MJ, Ribalta T. Brainderived neurotrophic factor in Huntington disease. Brain Res. 2000; 866:257-61. https://doi.org/10.1016/s0006-8993(00)02237-x PMID:10825501

22. Klein $A B$, Jennum $P$, Knudsen $S$, Gammeltoft $S$, Mikkelsen JD. Increased serum brain-derived neurotrophic factor (BDNF) levels in patients with narcolepsy. Neurosci Lett. 2013; 544:31-35. https://doi.org/10.1016/i.neulet.2013.03.031 PMID:23570723

23. Shimizu E, Hashimoto K, Okamura N, Koike K, Komatsu $\mathrm{N}$, Kumakiri C, Nakazato M, Watanabe H, Shinoda N, Okada S, lyo M. Alterations of serum levels of brainderived neurotrophic factor (BDNF) in depressed patients with or without antidepressants. Biol Psychiatry. 2003; 54:70-75.

https://doi.org/10.1016/s0006-3223(03)00181-1 PMID: 12842310

24. Hock C, Heese K, Hulette C, Rosenberg C, Otten U. Region-specific neurotrophin imbalances in Alzheimer disease: decreased levels of brain-derived neurotrophic factor and increased levels of nerve growth factor in hippocampus and cortical areas. Arch Neurol. 2000; 57:846-51.

https://doi.org/10.1001/archneur.57.6.846 PMID:10867782

25. Ng TK, Ho CS, Tam WW, Kua EH, Ho RC. Decreased Serum Brain-Derived Neurotrophic Factor (BDNF) Levels in Patients with Alzheimer's Disease (AD): A Systematic Review and Meta-Analysis. Int J Mol Sci. 2019; 20:257.

https://doi.org/10.3390/ijms20020257 PMID: $\underline{0634650}$

26. Kim BY, Lee SH, Graham PL, Angelucci F, Lucia A, Pareja-Galeano H, Leyhe T, Turana Y, Lee IR, Yoon JH, Shin JI. Peripheral Brain-Derived Neurotrophic Factor Levels in Alzheimer's Disease and Mild Cognitive Impairment: a Comprehensive Systematic Review and Meta-analysis. Mol Neurobiol. 2017; 54:7297-311. https://doi.org/10.1007/s12035-016-0192-9 
PMID:27815832

27. Qin XY, Cao C, Cawley NX, Liu TT, Yuan J, Loh YP, Cheng $Y$. Decreased peripheral brain-derived neurotrophic factor levels in Alzheimer's disease: a meta-analysis study (N=7277). Mol Psychiatry. 2017; 22:312-20. https://doi.org/10.1038/mp.2016.62 PMID:27113997

28. Balietti M, Giuli C, Conti F. Peripheral Blood BrainDerived Neurotrophic Factor as a Biomarker of Alzheimer's Disease: Are There Methodological Biases? Mol Neurobiol. 2018; 55:6661-72. https://doi.org/10.1007/s12035-017-0866-y PMID:29330839

29. Hashimoto K. Serum brain-derived neurotrophic factor as a predictor of incident dementia. JAMA Neurol. 2014; 71:653.

https://doi.org/10.1001/jamaneurol.2013.6414 PMID:24818682

30. O’Bryant SE, Hobson VL, Hall JR, Barber RC, Zhang S, Johnson L, Diaz-Arrastia R, and Texas Alzheimer's Research Consortium. Serum brain-derived neurotrophic factor levels are specifically associated with memory performance among Alzheimer's disease cases. Dement Geriatr Cogn Disord. 2011; 31:31-36. https://doi.org/10.1159/000321980 PMID:21135555

31. Ismail Z, Elbayoumi H, Fischer CE, Hogan DB, Millikin $\mathrm{CP}$, Schweizer T, Mortby ME, Smith EE, Patten SB, Fiest KM. Prevalence of Depression in Patients With Mild Cognitive Impairment: A Systematic Review and Metaanalysis. JAMA Psychiatry. 2017; 74:58-67. https://doi.org/10.1001/jamapsychiatry.2016.3162 PMID:27893026

32. Ma L. Depression, Anxiety, and Apathy in Mild Cognitive Impairment: Current Perspectives. Front Aging Neurosci. 2020; 12:9.

https://doi.org/10.3389/fnagi.2020.00009 PMID:32082139

33. Suliman S, Hemmings SM, Seedat S. Brain-Derived Neurotrophic Factor (BDNF) protein levels in anxiety disorders: systematic review and meta-regression analysis. Front Integr Neurosci. 2013; 7:55. https://doi.org/10.3389/fnint.2013.00055 PMID:23908608

34. Brunoni AR, Lopes M, Fregni F. A systematic review and meta-analysis of clinical studies on major depression and BDNF levels: implications for the role of neuroplasticity in depression. Int J Neuropsychopharmacol. 2008; 11:1169-80.

https://doi.org/10.1017/S1461145708009309 PMID: 18752720

35. Karege F, Bondolfi G, Gervasoni N, Schwald M, Aubry JM, Bertschy G. Low brain-derived neurotrophic factor (BDNF) levels in serum of depressed patients probably results from lowered platelet BDNF release unrelated to platelet reactivity. Biol Psychiatry. 2005; 57:1068-72.

https://doi.org/10.1016/j.biopsych.2005.01.008 PMID:15860348

36. Lu B. Pro-region of neurotrophins: role in synaptic modulation. Neuron. 2003; 39:735-38. https://doi.org/10.1016/s0896-6273(03)00538-5 PMID:12948441

37. Polacchini A, Metelli G, Francavilla R, Baj G, Florean M, Mascaretti LG, Tongiorgi E. A method for reproducible measurements of serum BDNF: comparison of the performance of six commercial assays. Sci Rep. 2015; 5:17989.

https://doi.org/10.1038/srep17989 PMID:26656852

38. O'Brien JT. The 'glucocorticoid cascade'hypothesis in man: prolonged stress may cause permanent brain damage. The British Journal of Psychiatry. 1997; 170:199-201.

https://doi.org/10.1192/S0007125000146513

39. Rogers J, Webster S, Lue LF, Brachova L, Civin WH, Emmerling $M$, Shivers B, Walker D, McGeer P. Inflammation and Alzheimer's disease pathogenesis. Neurobiol Aging. 1996; 17:681-86. https://doi.org/10.1016/0197-4580(96)00115-7 PMID:8892340

40. Tzu-Feng Wang TF, Tsai SF, Zhao ZW, Shih MM, Wang $\mathrm{CY}$, Yang TT, Kuo YM. Exercise-induced increases of corticosterone contribute to exercise-enhanced adult hippocampal neurogenesis in mice. Chin J Physiol. 2021; 64:186-93.

https://doi.org/10.4103/cjp.cjp_39 21

PMID:34472449

41. Wander CM, Song J. The neurogenic niche in Alzheimer's disease. Neurosci Lett. 2021; 762:136109. https://doi.org/10.1016/i.neulet.2021.136109 PMID:34271133

42. Cattaneo A, Macchi F, Plazzotta G, Veronica B, BocchioChiavetto L, Riva MA, Pariante CM. Inflammation and neuronal plasticity: a link between childhood trauma and depression pathogenesis. Front Cell Neurosci. 2015; 9:40.

https://doi.org/10.3389/fncel.2015.00040 PMID:25873859

43. Krogh J, Benros $M E$, Jørgensen $M B$, Vesterager $L$, Elfving $B$, Nordentoft $M$. The association between depressive symptoms, cognitive function, and inflammation in major depression. Brain Behav Immun. 2014; 35:70-76.

https://doi.org/10.1016/j.bbi.2013.08.014 
PMID:24016864

44. Osimo EF, Pillinger $\mathrm{T}$, Rodriguez IM, Khandaker GM, Pariante CM, Howes OD. Inflammatory markers in depression: A meta-analysis of mean differences and variability in 5,166 patients and 5,083 controls. Brain Behav Immun. 2020; 87:901-09.

https://doi.org/10.1016/i.bbi.2020.02.010 PMID:32113908

45. Osimo EF, Baxter $L$, Lewis G, Jones PB, Khandaker GM. Prevalence of low-grade inflammation in depression: a systematic review and meta-analysis of CRP levels. Psychol Med. 2019; 49:1958-70. https://doi.org/10.1017/S0033291719001454 PMID:31258105

46. Vogelzangs N, Beekman AT, de Jonge P, Penninx BW. Anxiety disorders and inflammation in a large adult cohort. Transl Psychiatry. 2013; 3:e249.

https://doi.org/10.1038/tp.2013.27 PMID:23612048

47. Uh D, Jeong HG, Choi KY, Oh SY, Lee S, Kim SH, Joe SH. Dehydroepiandrosterone Sulfate Level Varies Nonlinearly with Symptom Severity in Major Depressive Disorder. Clin Psychopharmacol Neurosci. 2017; 15:163-69.

https://doi.org/10.9758/cpn.2017.15.2.163 PMID:28449564

48. Ng TK, Tagawa A, Ho RC, Larbi A, Kua EH, Mahendran R, Carollo JJ, Heyn PC. Commonalities in biomarkers and phenotypes between mild cognitive impairment and cerebral palsy: a pilot exploratory study. Aging (Albany NY). 2021; 13:1773-816.

https://doi.org/10.18632/aging.202563

PMID:33497355

49. Martin CR, Preedy VR. Diagnosis and Management in Dementia: The Neuroscience of Dementia, Volume 1. Academic Press. 2020.

50. Xie B, Zhou H, Liu W, Yu W, Liu Z, Jiang L, Zhang R, Cui $D$, Shi Z, Xu S. Evaluation of the diagnostic value of peripheral BDNF levels for Alzheimer's disease and mild cognitive impairment: results of a meta-analysis. Int J Neurosci. 2020; 130:218-30.

https://doi.org/10.1080/00207454.2019.1667794 PMID:31518516

51. Lima Giacobbo B, Doorduin J, Klein HC, Dierckx RA, Bromberg E, de Vries EF. Brain-Derived Neurotrophic Factor in Brain Disorders: Focus on Neuroinflammation. Mol Neurobiol. 2019; 56:3295-312. https://doi.org/10.1007/s12035-018-1283-6 PMID:30117106

52. Khaodhiar L, Ling PR, Blackburn GL, Bistrian BR. Serum levels of interleukin-6 and C-reactive protein correlate with body mass index across the broad range of obesity. JPEN J Parenter Enteral Nutr. 2004;
28:410-15.

https://doi.org/10.1177/0148607104028006410 PMID:15568287

53. Williams MJ, Williams SM, Milne BJ, Hancox RJ, Poulton R. Association between C-reactive protein, metabolic cardiovascular risk factors, obesity and oral contraceptive use in young adults. Int J Obes Relat Metab Disord. 2004; 28:998-1003.

https://doi.org/10.1038/sj.ijo.0802713

PMID:15211365

54. Popp J, Wolfsgruber S, Heuser I, Peters O, Hüll $M$, Schröder J, Möller HJ, Lewczuk P, Schneider A, Jahn H, Luckhaus C, Perneczky R, Frölich L, et al. Cerebrospinal fluid cortisol and clinical disease progression in $\mathrm{MCl}$ and dementia of Alzheimer's type. Neurobiol Aging. 2015; 36:601-07.

https://doi.org/10.1016/j.neurobiolaging.2014.10.031 PMID:25435336

55. Venero C, Díaz-Mardomingo C, Pereda-Pérez I, GarcíaHerranz S, Utrera L, Valencia A, Peraita H. Increased morning salivary cortisol levels in older adults with nonamnestic and multidomain mild cognitive impairment. Psychoneuroendocrinology. 2013; 38:488-98.

https://doi.org/10.1016/j.psyneuen.2012.07.007 PMID:22857785

56. Miller GE, Chen E, Sze J, Marin T, Arevalo JM, Doll R, Ma R, Cole SW. A functional genomic fingerprint of chronic stress in humans: blunted glucocorticoid and increased NF-kappaB signaling. Biol Psychiatry. 2008; 64:266-72.

https://doi.org/10.1016/j.biopsych.2008.03.017 PMID:18440494

57. Ng A, Tam WW, Zhang MW, Ho CS, Husain SF, Mclntyre RS, Ho RC. IL-1 $\beta$, IL-6, TNF- $\alpha$ and CRP in Elderly Patients with Depression or Alzheimer's disease: Systematic Review and Meta-Analysis. Sci Rep. 2018; 8:12050.

https://doi.org/10.1038/s41598-018-30487-6

PMID:

58. Köhler-Forsberg O, Buttenschøn HN, Tansey KE, Maier W, Hauser J, Dernovsek MZ, Henigsberg N, Souery D, Farmer A, Rietschel M, McGuffin P, Aitchison KJ, Uher $\mathrm{R}$, Mors $\mathrm{O}$. Association between $\mathrm{C}$-reactive protein (CRP) with depression symptom severity and specific depressive symptoms in major depression. Brain Behav Immun. 2017; 62:344-50.

https://doi.org/10.1016/j.bbi.2017.02.020

PMID:28257825

59. Mattsson N, Andreasson U, Zetterberg H, Blennow K, and Alzheimer's Disease Neuroimaging Initiative. Association of Plasma Neurofilament Light With Neurodegeneration in Patients With Alzheimer 
Disease. JAMA Neurol. 2017; 74:557-66.

https://doi.org/10.1001/jamaneurol.2016.6117

PMID:28346578

60. Woolley JD, Strobl EV, Shelly WB, Karydas AM, Robin Ketelle RN, Wolkowitz OM, Miller BL, Rankin KP. BDNF serum concentrations show no relationship with diagnostic group or medication status in neurodegenerative disease. Curr Alzheimer Res. 2012; 9:815-21.

https://doi.org/10.2174/156720512802455395

PMID:21605064

61. Balietti M, Giuli C, Casoli T, Fabbietti P, Conti F. Is Blood Brain-Derived Neurotrophic Factor a Useful Biomarker to Monitor Mild Cognitive Impairment Patients? Rejuvenation Res. 2020; 23:411-19. https://doi.org/10.1089/rej.2020.2307 PMID:32200710

62. Sabbagh MN, Shi J, Lee M, Arnold L, Al-Hasan Y, Heim J, McGeer P. Salivary beta amyloid protein levels are detectable and differentiate patients with Alzheimer's disease dementia from normal controls: preliminary findings. BMC Neurol. 2018; 18:155.

https://doi.org/10.1186/s12883-018-1160-y

PMID:30257642

63. Bermejo-Pareja F, Antequera D, Vargas T, Molina JA, Carro E. Saliva levels of Abeta1-42 as potential biomarker of Alzheimer's disease: a pilot study. BMC Neurol. 2010; 10:108.

https://doi.org/10.1186/1471-2377-10-108

PMID:21047401

64. Strozyk D, Blennow K, White LR, Launer LJ. CSF Abeta 42 levels correlate with amyloid-neuropathology in a population-based autopsy study. Neurology. 2003; 60:652-56.

https://doi.org/10.1212/01.wnl.0000046581.81650.d0 PMID:12601108

65. Ng TK, Fam J, Feng L, Cheah IK, Tan CT, Nur F, Wee ST, Goh LG, Chow WL, Ho RC, Kua EH, Larbi A, Mahendran R. Mindfulness improves inflammatory biomarker levels in older adults with mild cognitive impairment: a randomized controlled trial. Transl Psychiatry. 2020; 10:21.

https://doi.org/10.1038/s41398-020-0696-y

PMID:32066726

66. Ng TK, Slowey PD, Beltran D, Ho RC, Kua EH, Mahendran R. Effect of mindfulness intervention versus health education program on salivary $A \beta-42$ levels in community-dwelling older adults with mild cognitive impairment: A randomized controlled trial. J Psychiatr Res. 2021; 136:619-25.

https://doi.org/10.1016/j.jpsychires.2020.10.038 PMID:33199051

67. American Psychiatric Association. Diagnostic and statistical manual of mental disorders (DSM- $5^{\circledR}$ ). American Psychiatric Pub. 2013.

https://doi.org/10.1176/appi.books.9780890425596

68. Chan HY, Ho RC, Mahendran R, Ng KS, Tam WW, Rawtaer I, Tan CH, Larbi A, Feng L, Sia A, Ng MK, Gan GL, Kua EH. Effects of horticultural therapy on elderly' health: protocol of a randomized controlled trial. BMC Geriatr. 2017; 17:192.

https://doi.org/10.1186/s12877-017-0588-z PMID:28851276

69. Ng KS, Sia A, Ng MK, Tan CT, Chan HY, Tan CH, Rawtaer I, Feng L, Mahendran R, Larbi A, Kua EH, Ho RC. Effects of Horticultural Therapy on Asian Older Adults: A Randomized Controlled Trial. Int J Environ Res Public Health. 2018; 15:1705.

https://doi.org/10.3390/ijerph15081705

PMID:30096932

70. Ng TK, Gan DR, Mahendran R, Kua EH, Ho RC. Social connectedness as a mediator for horticultural therapy's biological effect on community-dwelling older adults: Secondary analyses of a randomized controlled trial. Soc Sci Med. 2021; 284:114191. https://doi.org/10.1016/j.socscimed.2021.114191 PMID:34271401

71. Wong GC, Ng TK, Lee JL, Lim PY, Chua SK, Tan C, Chua M, Tan J, Lee S, Sia A, Ng MK, Mahendran R, Kua EH, et al. Horticultural Therapy Reduces Biomarkers of Immunosenescence and Inflammaging in CommunityDwelling Older Adults: A Feasibility Pilot Randomized Controlled Trial. J Gerontol A Biol Sci Med Sci. 2021; 76:307-17.

https://doi.org/10.1093/gerona/glaa271 PMID:33070170

72. Heyn PC, Tagawa A, Pan Z, Thomas S, Carollo JJ. Prevalence of metabolic syndrome and cardiovascular disease risk factors in adults with cerebral palsy. Dev Med Child Neurol. 2019; 61:477-83. https://doi.org/10.1111/dmcn.14148 PMID:30663044

73. Lee CK, Collinson SL, Feng L, Ng TP. Preliminary normative neuropsychological data for an elderly Chinese population. Clin Neuropsychol. 2012; 26:321-34.

https://doi.org/10.1080/13854046.2011.652180 PMID:22288384

74. Naegelin Y, Dingsdale H, Säuberli K, Schädelin S, Kappos L, Barde YA. Measuring and Validating the Levels of Brain-Derived Neurotrophic Factor in Human Serum. eNeuro. 2018; 5:ENEURO.041917.2018 .

https://doi.org/10.1523/ENEURO.0419-17.2018 PMID:29662942

75. Hanley JA, McNeil BJ. The meaning and use of the area 
under a receiver operating characteristic (ROC) curve. Radiology. 1982; 143:29-36.

https://doi.org/10.1148/radiology.143.1.7063747

PMID:은

76. Kallner A. Laboratory statistics: methods in chemistry and health sciences. Elsevier. 2017.

77. Sedgwick P. Multiple significance tests: the Bonferroni correction. BMJ. 2012; 344:e509. https://doi.org/10.1136/bmj.e509

78. Althouse AD. Adjust for Multiple Comparisons? It's Not That Simple. Ann Thorac Surg. 2016; 101:1644-45. https://doi.org/10.1016/j.athoracsur.2015.11.024 PMID:27106412 


\section{SUPPLEMENTARY MATERIALS}

\section{Supplementary Methods}

\section{CP cohort inclusion and exclusion criteria [1-6]}

Participants were included in the study if they were (1) interested and able to participate in the study and (2) able to walk across a 35 -foot $(10.6 \mathrm{~m})$ walkway, with or without assistive devices, at least three times.

\section{Determining cases with probable MDD and GAD across different cohorts}

For all cases of probable major depressive disorder (MDD) and probable generalized anxiety disorder (GAD), we used the respective cut-off points for each of the scales employed in the respective cohorts. Each cohort has different scales and hence we employed the scales' respective established cut-offs for establishing probable cases.

\section{MCI cohort}

\section{GDS}

The 15-item Geriatric Depression Scales (GDS) was used to assess depressive symptoms. The participants rated 15 items with either Yes (1) or No (0) response categories. The possible scores range from zero to 15 , with a higher score indicating a higher depressive symptom. The cut-off for probable MDD was established as GDS $\geq 5$ [7].

\section{GAI}

The 20-item Geriatric Anxiety Inventory (GAI) was used to assess anxiety symptoms [8]. The participants rated the items with either agree (1) or disagree (0). The possible scores range from zero to 20 , with a higher score indicating a higher anxiety symptom. The cut-off for probable GAD was established as $\mathrm{GAI} \geq 9$ [8].

\section{HC cohort}

For both the Zung's instruments, they are 20-item assessments of depressive and anxiety symptoms. Participants rated each item depending on how they felt during the past week using a 4-point likert scale ranging from 1 to 4 . A higher score indicated more severe symptoms. The cut-offs were $\mathrm{SDS} \geq 42$ and $\mathrm{SAS} \geq 36$ based on previous studies $[9,10]$.

\section{CP cohort}

\section{CES-D}

A higher total score indicated a higher number of depressive symptoms. The cut-off was set at $\geq 16$ [11].
Furthermore, using the Structured Clinical Interview for Diagnostic and Statistical Manual of Mental Disorders, Revised Third Edition (SCID), the "gold standard" clinical tool for diagnosing depression, CES-D has high sensitivity (92\%-100\%) and specificity $(84 \%-87 \%)$ in correctly classifying cases with depression $[12,13]$.

\section{PROMIS emotional distress — anxiety— short form}

Subjects were asked questionnaire to assess anxiety symptoms during the past 7 days on a 5-point likert scale ranging from 0-5. A higher score indicated a higher anxiety symptoms. The raw scores were then converted into T-scores. A cut-off of T-scores $\geq 55$ indicated some level of clinically-significant anxiety [14].

\section{Supplementary References}

1. Baer HR, Thomas SP, Pan Z, Tagawa A, Carollo JJ, Heyn PC. Self-reported physical function is associated with walking speed in adults with cerebral palsy. J Pediatr Rehabil Med. 2019; 12:181-88. https://doi.org/10.3233/PRM-180585 PMID: $\underline{31227669}$

2. Carollo J, Tagawa A, Bodkin A, Pan Z, Heyn PC. Analysis of walking in individuals with $\mathrm{CP}$ during transition to adulthood: From The Cpat Study. Arch Phys Med Rehabil. 2018; 99: e72.

https://doi.org/10.1016/j.apmr.2018.07.254

3. Heyn P, Robertson D, Pan Z, Carollo J. Examination of premature aging in individuals with cerebral palsy by self-reported health status. The Gerontologist. 2016; 56:471. https://doi.org/10.1093/geront/gnw162.1890

4. Heyn P, Tagawa A, Pan Z, Bodkin A, Carollo J. Association Between Gait Speed and Cognitive Function in Adults with Cerebral Palsy. Arch Phys Med Rehabil. 2017; 98: e35-6.

5. Heyn PC, Tagawa A, Pan Z, Thomas S, Carollo JJ. Prevalence of metabolic syndrome and cardiovascular disease risk factors in adults with cerebral palsy. Dev Med Child Neurol. 2019; 61:477-83. https://doi.org/10.1111/dmcn.14148 PMID:30663044

6. Oliveira T, Carollo J, Robertson D, Pan Z, Heyn P. Incidence of Epilepsy in Adults with Cerebral Palsy and Secondary Health Outcomes: A Review and Proposed Feasibility Study. J Neurol Disord. 2014; 2: 2.

7. Yesavage JA, Brink TL, Rose TL, Lum O, Huang V, Adey $M$, Leirer VO. Development and validation of a geriatric depression screening scale: a preliminary report. J Psychiatr Res. 1982; 17:37-49. 
https://doi.org/10.1016/0022-3956(82)90033-4

PMID:7183759

8. Pachana NA, Byrne GJ, Siddle H, Koloski N, Harley E, Arnold E. Development and validation of the Geriatric Anxiety Inventory. Int Psychogeriatr. 2007; 19:103-14. https://doi.org/10.1017/S1041610206003504 PMID: 16805925

9. Dunstan DA, Scott N. Clarification of the cut-off score for Zung's self-rating depression scale. BMC Psychiatry. 2019; 19:177.

https://doi.org/10.1186/s12888-019-2161-0 PMID:31185948

10. Dunstan DA, Scott N. Norms for Zung's Self-rating Anxiety Scale. BMC Psychiatry. 2020; 20:90. https://doi.org/10.1186/s12888-019-2427-6 PMID:32111187

11. Vilagut G, Forero CG, Barbaglia G, Alonso J. Screening for Depression in the General Population with the Center for Epidemiologic Studies Depression (CES-D): A
Systematic Review with Meta-Analysis. PLoS One. 2016; 11:e0155431.

https://doi.org/10.1371/journal.pone.0155431

PMID:27182821

12. Spitzer RL, Williams JB, Gibbon $M$, First MB. The Structured Clinical Interview for DSM-III-R (SCID). I: History, rationale, and description. Arch Gen Psychiatry. 1992; 49:624-29.

https://doi.org/10.1001/archpsyc.1992.018200800320 05 PMID:1637252

13. Lyness JM, Noel TK, Cox C, King DA, Conwell Y, Caine ED. Screening for depression in elderly primary care patients. A comparison of the Center for Epidemiologic Studies-Depression Scale and the Geriatric Depression Scale. Arch Intern Med. 1997; 157:449-54.

PMID: 9046897

14. American Psychiatric Association. Diagnostic and statistical manual of mental disorders (DSM- $\left.5^{\circledR}\right)$. American Psychiatric Pub. 2013. 


\section{Supplementary Tables}

Supplementary Table 1. Linear regressions between biomarkers (dependent variables) separately with dummy variable indicating cohort (and diagnostic) status, i.e. $\mathrm{MCl}$ and $\mathrm{HC}$ (independent variable).

\begin{tabular}{|c|c|c|c|c|}
\hline Biomarkers & Models & $\beta(95 \%$ CI $)$ & $P$ value & $R^{2}$ \\
\hline \multirow{3}{*}{ BDNF } & 1 & $0.53(0.40$ to 0.66$)$ & $<0.001 * * *$ & 0.41 \\
\hline & 2 & $0.48(0.34$ to 0.63$)$ & $<0.001 * * *$ & 0.43 \\
\hline & 3 & $0.47(0.32$ to 0.62$)$ & $<0.001 * * *$ & 0.44 \\
\hline \multirow{3}{*}{ Hs-CRP } & 1 & 0.27 (0.09 to 0.44$)$ & $0.004 * *$ & 0.09 \\
\hline & 2 & 0.27 (0.07 to 0.47$)$ & $0.009 * *$ & 0.10 \\
\hline & 3 & $0.22(0.03$ to 0.41$)$ & $0.027 *$ & 0.26 \\
\hline \multirow{3}{*}{ DHEA-S } & 1 & $0.08(-0.12$ to 0.27$)$ & 0.45 & 0.006 \\
\hline & 2 & $0.06(-0.08$ to 0.20$)$ & 0.42 & 0.60 \\
\hline & 3 & $0.06(-0.08$ to 0.21$)$ & 0.39 & 0.61 \\
\hline
\end{tabular}

Notes: BDNF, Brain-derived neurotrophic factor; Hs-CRP, High-sensitivity C-reactive Protein; DHEA-S, Dehydroepiandrosterone sulfate.

$95 \% \mathrm{Cl}=95 \%$ confidence interval, $*$ indicates $\mathrm{p}<0.05, * * *$ indicates $\mathrm{p}<0.01$, and $* * *$ indicates $\mathrm{p}<0.001$.

Model 1: bivariate association.

Model 2: added age, sex, years of formal education.

Model 3: added body-mass index and the total number of chronic diseases.

Supplementary Table 2A. Biomarker levels for each analysis and their discriminative accuracies for probable MDD.

\begin{tabular}{|c|c|c|c|c|c|c|c|c|c|c|c|}
\hline & \multirow{3}{*}{$\begin{array}{c}\text { Inclusion of } \\
\text { clinically- } \\
\text { diagnosed MCI? }\end{array}$} & \multirow{3}{*}{ Biomarkers* } & \multicolumn{5}{|c|}{ Biomarker levels (compared to control) } & \multicolumn{4}{|c|}{ Discriminative accuracies } \\
\hline & & & \multicolumn{2}{|c|}{ Probable MDD } & \multicolumn{2}{|c|}{ Control } & \multirow{2}{*}{ P-value } & \multirow{2}{*}{ AUC } & \multirow{2}{*}{$\mathbf{S E}$} & \multirow{2}{*}{$\begin{array}{c}95 \% \text { CI of } \\
\text { AUC } \\
\end{array}$} & \multirow{2}{*}{ P-value } \\
\hline & & & $\mathbf{n}$ & Mean (SD) & $\mathbf{n}$ & Mean (SD) & & & & & \\
\hline \multirow{4}{*}{$\begin{array}{l}\text { CP cohort } \\
\text { included }\end{array}$} & Included & BDNF & 24 & $2.75(0.70)$ & 135 & $2.53(0.57)$ & 0.096 & 0.64 & 0.06 & 0.51 to 0.76 & $0.032 *$ \\
\hline & & hs-CRP & 26 & $20.25(0.47)$ & 143 & $-0.04(0.51)$ & $0.009 * *$ & 0.69 & 0.06 & 0.58 to 0.80 & $0.003 * *$ \\
\hline & Excluded & BDNF & 13 & $2.31(0.64)$ & 106 & $2.36(0.49)$ & 0.753 & 0.53 & 0.08 & 0.36 to 0.69 & 0.772 \\
\hline & & hs-CRP & 15 & $0.23(0.51)$ & 112 & $-0.09(0.51)$ & $\mathbf{0 . 0 2 0} * *$ & 0.74 & 0.08 & 0.58 to 0.89 & $0.005 * *$ \\
\hline \multirow{4}{*}{$\begin{array}{l}\text { CP cohort } \\
\text { excluded }\end{array}$} & & DHEA-S & 14 & $2.60(0.52)$ & 84 & $2.39(0.47)$ & 0.126 & 0.62 & 0.09 & 0.45 to 0.80 & 0.152 \\
\hline & Excluded & BDNF & 3 & $2.73(0.02)$ & 53 & $2.65(0.28)$ & $0.048^{*}$ & 0.62 & 0.07 & 0.49 to 0.75 & 0.478 \\
\hline & & hs-CRP & 3 & $0.44(0.16)$ & 53 & $-0.09(0.43)$ & $0.036^{*}$ & 0.91 & 0.05 & 0.81 to 1.00 & 0.019* \\
\hline & & DHEA-S & 3 & $2.44(0.49)$ & 53 & $2.38(0.45)$ & 0.840 & 0.53 & 0.16 & 0.22 to 0.83 & 0.870 \\
\hline
\end{tabular}


Supplementary Table 2B. Biomarker levels for each analysis and their discriminative accuracies for probable GAD.

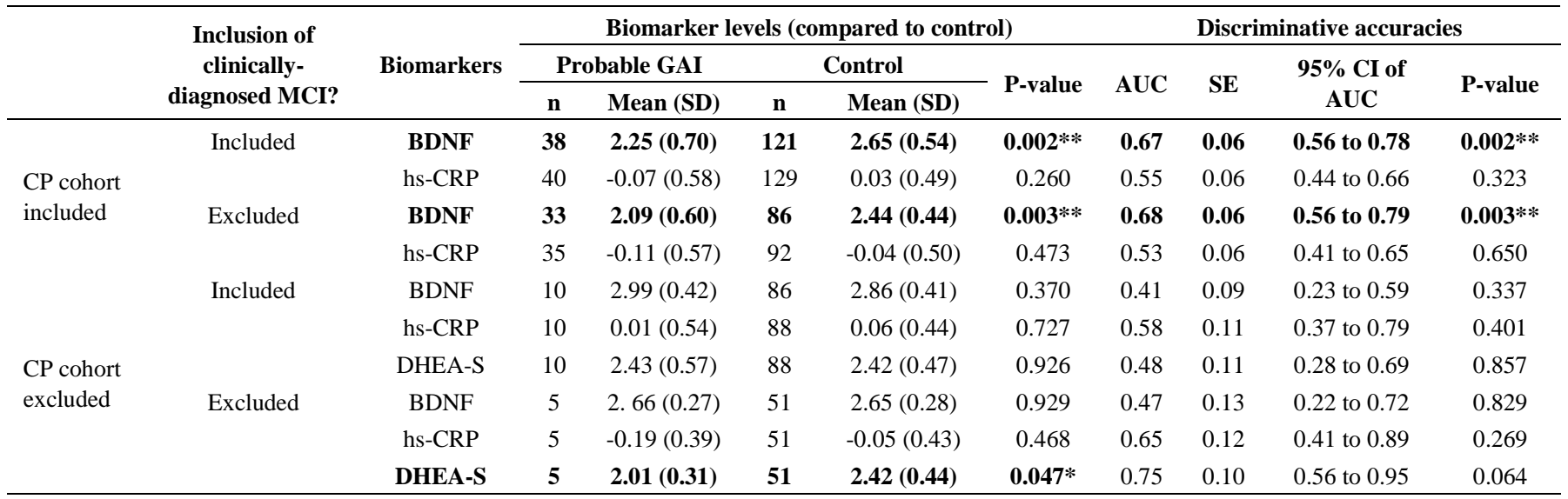

Footnote: in contrast to $\mathrm{MCl}$ and probable MDD (higher values), AUC curves were generated with the lower values of the biomarkers discriminating probable GAD from other conditions.

Supplementary Table 2C. Biomarker levels for each analysis and their discriminative accuracies for CP.

\begin{tabular}{|c|c|c|c|c|c|c|c|c|c|c|c|}
\hline & \multirow{3}{*}{$\begin{array}{c}\text { Inclusion of } \\
\text { probable MDD } \\
\text { and GAD? }\end{array}$} & \multirow{3}{*}{ Biomarkers } & \multicolumn{5}{|c|}{ Biomarker levels (compared to control) } & \multicolumn{4}{|c|}{ Discriminative accuracies } \\
\hline & & & \multicolumn{2}{|c|}{$\begin{array}{l}\text { Clinically diagnosed } \\
\text { CP }\end{array}$} & \multicolumn{2}{|c|}{ Control } & \multirow[t]{2}{*}{ P-value } & \multirow[t]{2}{*}{ AUC } & \multirow[t]{2}{*}{$\mathbf{S E}$} & \multirow{2}{*}{$\begin{array}{c}95 \% \text { CI of } \\
\text { AUC }\end{array}$} & \multirow[t]{2}{*}{ P-value } \\
\hline & & & $\mathbf{n}$ & Mean (SD) & $\mathbf{n}$ & Mean (SD) & & & & & \\
\hline \multirow{4}{*}{$\begin{array}{l}\text { MCI cohort } \\
\text { included }\end{array}$} & Included & BDNF & 64 & $2.07(0.52)$ & 96 & $2.87(0.04)$ & $<0.001 * * *$ & 0.88 & 0.03 & 0.83 to 0.94 & $<0.001 * * *$ \\
\hline & & hs-CRP & 72 & $-0.05(0.58)$ & 98 & $0.05(0.45)$ & 0.210 & 0.57 & 0.05 & 0.48 to 0.67 & 0.130 \\
\hline & Excluded & BDNF & 32 & $2.15(0.45)$ & 76 & $2.84(0.42)$ & $<0.001 * * *$ & 0.87 & 0.04 & 0.79 to 0.95 & $<0.001 * * *$ \\
\hline & & hs-CRP & 37 & $-0.05(0.57)$ & 78 & $0.03(0.45)$ & 0.397 & 0.59 & 0.07 & 0.46 to 0.72 & 0.150 \\
\hline \multirow{4}{*}{$\begin{array}{l}\text { MCI cohort } \\
\text { excluded }\end{array}$} & Included & BDNF & 64 & $2.07(0.52)$ & 56 & $2.65(0.27)$ & $<0.001 * * *$ & 0.83 & 0.04 & 0.76 to 0.91 & $<0.001 * * *$ \\
\hline & & hs-CRP & 72 & $-0.05(0.58)$ & 56 & $-0.06(0.43)$ & 0.902 & 0.52 & 0.05 & 0.41 to 0.62 & 0.740 \\
\hline & Excluded & BDNF & 32 & $2.15(0.45)$ & 48 & $2.65(0.28)$ & $<0.001 * * *$ & 0.82 & 0.05 & 0.72 to 0.93 & $<0.001 * * *$ \\
\hline & & hs-CRP & 37 & $-0.05(0.57)$ & 48 & $-0.08(0.43)$ & 0.820 & 0.54 & 0.07 & 0.40 to 0.68 & 0.549 \\
\hline
\end{tabular}

Footnote: in contrast to $\mathrm{MCl}$ and probable MDD (higher values for discriminating the conditions) and similar to probable GAD, AUC curves were generated with the lower values of the biomarkers discriminating CP from other conditions. DHEA-S was not examined in the CP cohort and hence was not presented in this table. 
Supplementary Table 3. Neurocognitive test and its associated cognitive domain(s) and task description.

\begin{tabular}{|c|c|c|}
\hline Neurocognitive test & Cognitive domain(s) & Task description \\
\hline RAVLT [1] & $\begin{array}{l}\text { Declarative verbal } \\
\text { learning and memory } \\
\text { (immediate, delayed, } \\
\text { and recognition) }\end{array}$ & $\begin{array}{l}\text { Participants were given a list of } 15 \text { unrelated words (list A) to learn and } \\
\text { immediately recall aloud over five learning trials (Immediate Recall). } \\
\text { Subsequently, an interference list of } 15 \text { unrelated words (list B) was } \\
\text { presented only once for the participants to learn and recall immediately. } \\
\text { After which, participants were instructed to recall aloud the words from list } \\
\text { A. Approximately } 30 \text { minutes later, they were again asked to recall aloud the } \\
\text { words from list A (Delayed Recall). Finally, participants were given a list of } \\
50 \text { words, comprising list A, list B, and } 20 \text { new distractor words, from which } \\
\text { they had to identify the original } 15 \text { words (Recognition). } \\
\text { Eight outcome measures were used in RAVLT. RAVLT T1 and RAVLT T5 } \\
\text { referred to the total number of words correctly recalled in the first and fifth } \\
\text { learning trials from list A during Immediate Recall. RAVLT B referred to } \\
\text { the total number of words correctly recalled from the interference list. } \\
\text { RAVLT T6 referred to the total number of words correctly recalled from list } \\
\text { A during Delayed Recall. Lastly, RAVLT Recognition Trial and RAVLT } \\
\text { Recognition Trail - False Positive referred to the total number of words } \\
\text { correctly identified and falsely identified from list A during Recognition. }\end{array}$ \\
\hline $\begin{array}{l}\text { Digit Span Forward } \\
\text { and Backward Task }\end{array}$ & $\begin{array}{c}\text { Attention and } \\
\text { working memory }\end{array}$ & $\begin{array}{l}\text { The Digit Span Forward and Backward Task are subtests from the Wechsler } \\
\text { Adult Intelligence Scale III (WAIS-III) [2]. A series of numbers were read } \\
\text { aloud by the assessor, of which participants were required to repeat the } \\
\text { series of numbers in the same (forward) or reverse (backward) order. The } \\
\text { forward trial measures working memory span specifically, while the } \\
\text { backward trial involved manipulation of information in the working } \\
\text { memory. Two outcome measures were used in the Digit Span Task. Forward } \\
\text { and Backward scores were obtained from the total number of forward and } \\
\text { backward trials successfully repeated by the participants, respectively. }\end{array}$ \\
\hline CTT [3] & Divided attention & $\begin{array}{l}\text { The CTT consists of two parts. In the first (CTT1), participants connected a } \\
\text { series of numbers that were printed within pink and yellow circles, } \\
\text { sequentially from } 1 \text { to } 25 \text {. In the second part (CTT2), participants similarly } \\
\text { connected the numbers from } 1 \text { to } 25 \text {, but alternated between choosing } \\
\text { numbers in either pink or yellow circles. Three outcome measures were } \\
\text { obtained from CTT - completion time for CTT1 and CTT2, and interference } \\
\text { effect (i.e. CTT interference), which was calculated as the difference in } \\
\text { completion times between CTT1 and CTT2, divided by CTT1. }\end{array}$ \\
\hline Block Design Test & Visuospatial function & $\begin{array}{l}\text { The Block Design Test is a subtest from the WAIS-III [2]. Here, participants } \\
\text { were instructed to arrange blocks with red and white patterns on different } \\
\text { sides to match the required block patterns in each trial. Scoring for the block } \\
\text { design test depended on both the accuracy in matching the patterns and } \\
\text { speed. Additional points were awarded to participants if they completed the } \\
\text { trials within various time limits. }\end{array}$ \\
\hline $\begin{array}{l}\text { Semantic Fluency } \\
\text { (Animal) Test [4] }\end{array}$ & Verbal fluency & $\begin{array}{l}\text { Participants were instructed to name as many different animals as they could } \\
\text { in one minute. The total score was indicated by the total number of correct } \\
\text { and unique animal names. }\end{array}$ \\
\hline
\end{tabular}

Notes: RAVLT, Rey Auditory Verbal Learning Test; CTT, Color Trails Test.

\section{Supplementary References}

1. Rey A. L'examen psychologique dans les cas d'encéphalopathie traumatique. (Les problems.). Arch Psychol. Editions Médecine et Hygiène. 1941.

2. Wechsler D. WAiS-iii. Psychological Corporation San Antonio, TX. 1997.

3. D’Elia L, Satz P, Uchiyama C, White T. Psychological Assessment Resources. Inc California. 1994.

4. Lezak MD, Howieson DB, Loring DW, Fischer JS. Neuropsychological assessment. Oxford University Press, USA. 2004. 